\title{
WestVirginiaUniversity
}

THE RESEARCH REPOSITORY @ WVU

Graduate Theses, Dissertations, and Problem Reports

2013

\section{A Comparison of Responses and Exteroceptive Stimuli as Time Markers}

Adam E. Fox

West Virginia University

Follow this and additional works at: https://researchrepository.wvu.edu/etd

\section{Recommended Citation}

Fox, Adam E., "A Comparison of Responses and Exteroceptive Stimuli as Time Markers" (2013). Graduate Theses, Dissertations, and Problem Reports. 4967.

https://researchrepository.wvu.edu/etd/4967

This Dissertation is protected by copyright and/or related rights. It has been brought to you by the The Research Repository @ WVU with permission from the rights-holder(s). You are free to use this Dissertation in any way that is permitted by the copyright and related rights legislation that applies to your use. For other uses you must obtain permission from the rights-holder(s) directly, unless additional rights are indicated by a Creative Commons license in the record and/ or on the work itself. This Dissertation has been accepted for inclusion in WVU Graduate Theses, Dissertations, and Problem Reports collection by an authorized administrator of The Research Repository @ WVU.

For more information, please contact researchrepository@mail.wvu.edu. 
A Comparison of Responses and Exteroceptive Stimuli as Time Markers

\title{
Adam E. Fox
}

Dissertation submitted to the Eberly College of Arts and Sciences at West Virginia University in partial fulfillment of the requirements

for the degree of

Doctor of Philosophy

in

Psychology

\author{
Elizabeth G. E. Kyonka, Ph.D., Chair \\ Karen G. Anderson, Ph.D. \\ Michael Perone, Ph.D. \\ Miranda N. Reed, Ph.D. \\ Jim H. Belanger, Ph.D.
}

Department of Psychology

Morgantown, West Virginia

2013

Keywords: Response-Initiated Fixed-Interval; Temporal Discrimination; Time Markers; Postreinforcement Pause; Pigeons; Key Peck 


\section{Abstract \\ A Comparison of Responses and Exteroceptive Stimuli as Time Markers}

\section{Adam E. Fox}

Time markers are events that are predictive of when future events will occur. Different events can serve as time markers that initiate intervals in schedules of reinforcement. Pigeons were exposed to fixed-interval (FI) schedules in which the onset of the interval was signaled by the illumination of a key light, initiated by a peck to a lighted key, or a combination of both events. In these variations of fixed-interval schedules, food was delivered contingent on the first response after the interval elapsed. In Experiment 1, three pigeons were exposed to a multiple schedule. One component was a standard FI schedule; key light illumination signaled the onset of the interval. The other component was a response-initiated fixed-interval (RIFI) schedule; the first key-peck response determined the onset of the interval. In Experiment 2, three pigeons were exposed to a multiple FI-RIFI schedule of reinforcement and on occasional trials food was not delivered (i.e., "no-food" or "peak trials"). A yoking procedure equated reinforcement rates between the schedule types in both Experiments 1 and 2. First-response latencies were longer and absolute response rates early in the schedules were higher in the RIFI schedules in Experiments 1 and 2. Normalized response-rate gradients, ogive fits, and breakpoints were equivalent for the schedule types in Experiment 1, indicating no differences in temporal discrimination. However, the duration of responding at a high rate was longer in no-food trials of RIFI schedules than no-food trials of FI schedules in Experiment 2, which suggests that temporal discrimination precision was reduced in the RIFI schedules. In Experiment 3, three pigeons were exposed to FI, RIFI, and Signaled-RIFI schedules of reinforcement. In Signaled-RIFI schedules, the interval-initiating response was associated with a key-light color and location change. Firstresponse latencies were shorter in the Signaled-RIFI schedules than in the FI and RIFI schedules. Reinforcement rates were highest in the FI schedules, and higher in the Signaled-RIFI schedules than the RIFI schedules - a result of the relatively shorter first-response latencies. Normalized response-rate gradients, ogive fits, and breakpoints revealed no significant differences in temporal discrimination between the schedule types. However, response-rate gradients and breakpoints in the Signaled-RIFI schedules were more similar to those obtained in the FI than RIFI schedules. Although current models of interval timing do not include parameters for the dimension of time markers, the results of Experiment 2 indicate that time marker dimension may affect temporal discrimination precision and that responses may be less efficacious time markers than exteroceptive stimuli. 


\section{Acknowledgements}

This dissertation was supported through doctoral research funds provided by the Eberly College of Arts and Sciences and the Department of Psychology at West Virginia University. I would like to thank the members of my dissertation committee: Karen Anderson, Mike Perone, Miranda Reed, and Jim Belanger. I am especially grateful to Liz Kyonka for serving as chair of the committee and as my advisor for the past three years. A special thanks to all the members of the Quantitative Analysis of Behavior Laboratory at WVU. 


\section{Table of Contents}

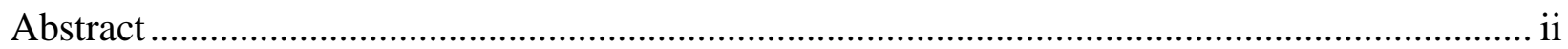

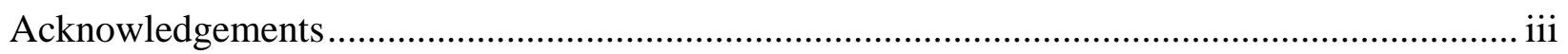

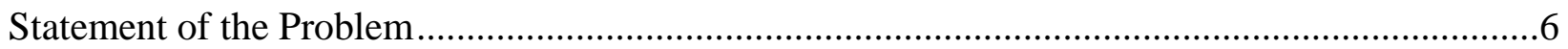

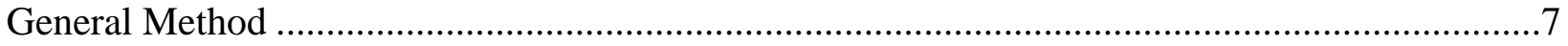

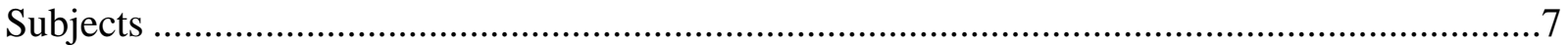

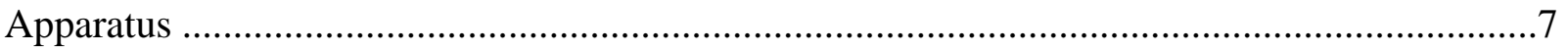

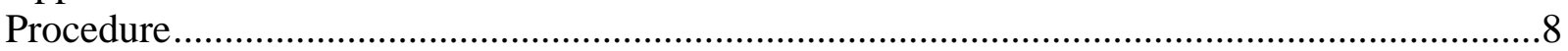

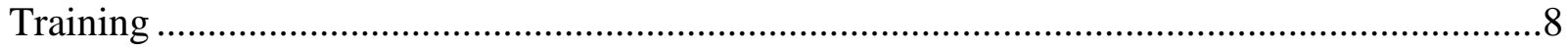

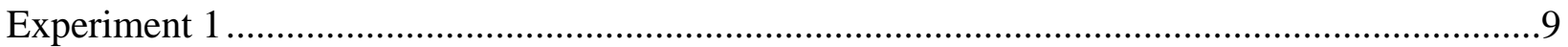

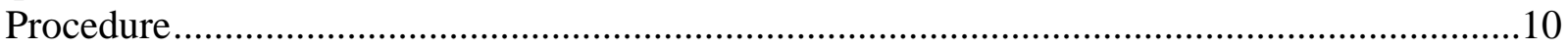

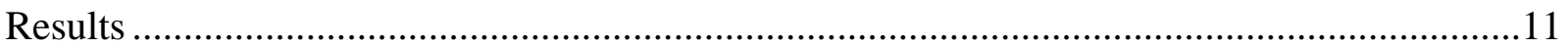

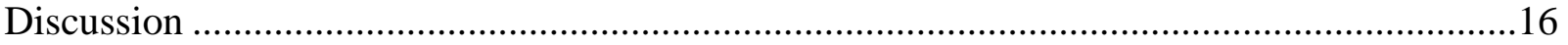

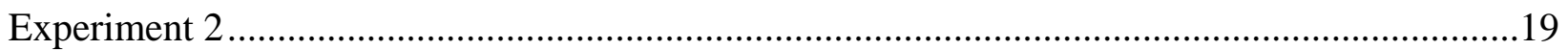

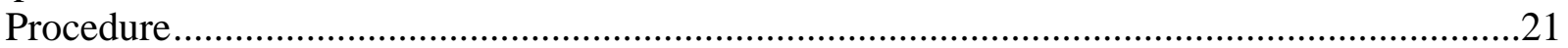

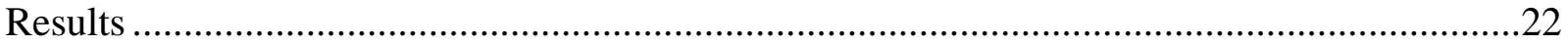

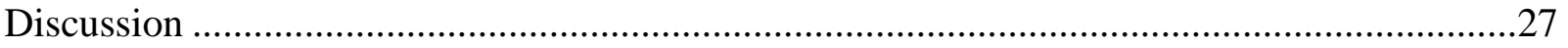

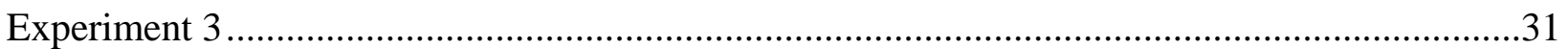

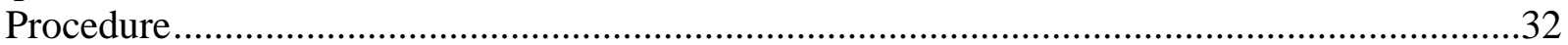

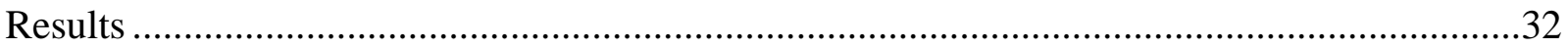

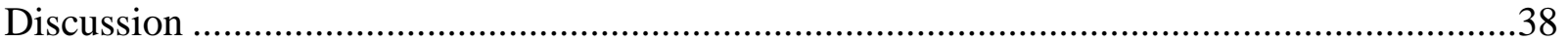

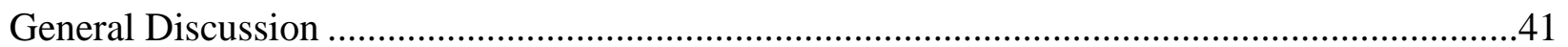

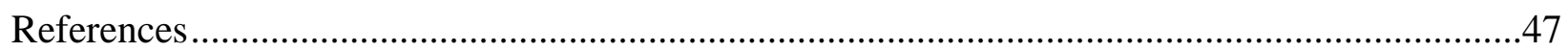

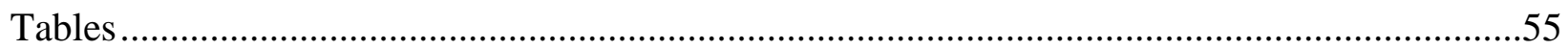

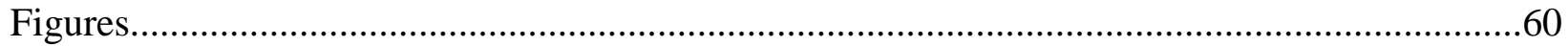

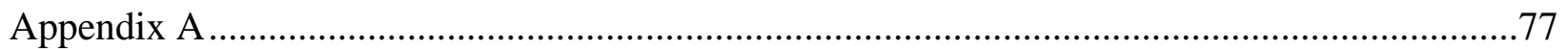

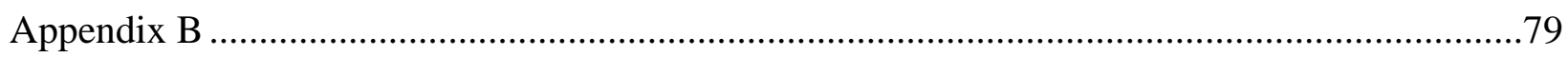




\section{A Comparison of Responses and Exteroceptive Stimuli as Time Markers}

Anticipating when important events will occur and effectively deciding when to engage in particular responses underlie adaptive behavior. Organisms must use past events—-time markers - as cues for when future events will occur and for when to engage in particular forms of behavior. Sometimes those time markers are exteroceptive stimuli (e.g., a traffic light turns yellow) and sometimes those events are behavior associated with no exteroceptive stimulus change (e.g., pressing a cross-walk button). There is currently a lack of understanding in how the dimensions of these time markers affect future behavior that relies on them. It is possible that responses and exteroceptive stimuli differentially control future behavior. For example, a response may be a more salient time marker (i.e., result in more accurate and precise temporal control of behavior) than an exteroceptive stimulus change because it requires action from the subject. The overarching objective of this dissertation is a quantitative comparison of pigeon key pecking in interval schedules when responses and exteroceptive stimuli serve as time markers. Understanding whether differences in these two types of time markers affect temporal discrimination is important for developing treatments for many psycho-neurological impairments. Inabilities to accurately anticipate when predictable events will occur in the environment are associated with, for example, schizophrenia (see Ward, Kellendonk, Kandel, \& Balsam, 2012), Parkinson’s disease (e.g., Rammsayer \& Classen, 1997), and autism spectrum disorders (e.g., Allman, DeLeon, \& Wearden, 2011).

Temporal discrimination-discriminating the duration of some timed interval or the temporal dimensions of some event in time-is most often evaluated behaviorally using fixedinterval (FI) schedules of reinforcement (see Guilhardi \& Church, 2004). In FI schedules a reinforcer (e.g., food) is delivered contingent on the first response after some fixed interval has 
elapsed (Skinner, 1938). Temporal discrimination in FI schedules is most often evaluated by measuring the rate at which the response that produces the reinforcer occurs as time to the availability of the reinforcer decreases—although, other measures are often employed depending on the research objective (for a review of typical findings and analyses employed see Guilhardi \& Church, 2004). For example, consider an FI 15-s schedule in which food is delivered contingent on the first response after $15 \mathrm{~s}$. If a single response occurs between 15 and $15.5 \mathrm{~s}$, behavior may be classified as being under relatively good temporal control. Alternatively, if responses occur at a constant rate throughout the 15-s interval, behavior may be classified as being under relatively poor temporal control.

In typical FI procedures, the onset of the interval to food availability is most often marked in time or signaled to the organism via an exteroceptive stimulus change such as the illumination of a light (e.g., Dews, 1978; Nevin, 1971), delivery of a reinforcer (e.g., Catania \& Reynolds, 1968; Lejeune \& Wearden, 1991), or the onset of an auditory stimulus (e.g., Guilhardi \& Church, 2005; Roberts \& Church, 1978). These stimuli have likely been chosen because they are controlled procedurally by the experimenter and there is an underlying assumption that they function equivalently to other, less controlled options, like a response (see Buhusi \& Meck, 2000). Relatively little research has directly compared temporal discrimination during intervals initiated via the onset of an exteroceptive stimulus and intervals initiated via a response. Only two studies have explicitly compared responses and exteroceptive stimulus changes as time markers experimentally (Caetano \& Church, 2009; Fox \& Kyonka, 2013). The results of both experiments suggest responses and stimuli function similarly as time markers, however, procedural idiosyncrasies limit the generality of those findings. Therefore, the purpose of the three experiments presented here was to quantitatively compare temporal discrimination during 
fixed intervals to response-contingent food when key-light illumination, a key-peck response, or a combination of both marked the onset of the intervals.

Temporal discrimination research using FI schedules is extensive (e.g., Dews, 1978;

Gentry, Weiss, \& Laties, 1983; Lejeune \& Wearden, 1991). In these procedures, temporal discrimination is most often evaluated using response-rate gradients—response rate as a function of time to food. In these studies, response rate typically increases as time to food decreases in an ogive pattern when responding is aggregated across multiple trials.

Response-initiated fixed-interval (RIFI) schedules are procedurally similar to FI schedules except the interval to food does not start timing down until the first response on a trial. In comparison to temporal discrimination research using FI schedules, research using schedules in which a response is required to initiate the interval to reinforcer availability has been much less widespread. Research using RIFI schedules, which are also referred to as tandem FR 1-FI schedules (e.g., Shull, 1970a) and, in experimental behavioral ecology, self-initiated fixedinterval schedules (e.g., Vasconcelos \& Urcuioli, 2008), has found behavior to be somewhat similar to that observed under FI schedules. Although absolute response rates tend to be higher early in RIFI than FI schedules of the same duration, response rates in RIFI schedules increase as time to food decreases in a similar ogival pattern when responding is aggregated across multiple trials (Fox \& Kyonka, 2013).

In both FI (Schneider, 1969) and RIFI schedules (Mechner, Guevrekian, \& Mechner, 1963; Shull, 1970a), responding tends to be characterized by a "low-high” pattern on individual trials. The "low-high" pattern is a period of disengagement (few or no target responses) at the beginning of a trial, followed by a period of engagement toward the end of the trial as time to food decreases. The mean duration of these low periods, or the point of transition from the low 
period to the high period on individual trials, is not systematically different in FI and RIFI schedules (Fox \& Kyonka, 2013).

First-response latency, the period of time after reinforcer delivery and the start of the subsequent trial during which no responding occurs, is a positive function of the interval duration under both FI and RIFI schedules (Chung \& Neuringer, 1967; Lowe, Davey, \& Harzem, 1974; Shull, 1970a; Weaver \& Branch, 2008). First-response latencies are not necessarily equivalent to the end of the "low" period of a trial described above. During the "low" period responding can occur, albeit by definition at a relatively low rate; the first-response latency is defined as the period of time during which no responding is occurring after trial onset and typically makes up just a portion of the "low" period on any given trial.

None of the aforementioned research sought to compare temporal discrimination between intervals initiated by an exteroceptive stimulus change and intervals initiated by a response. To date, two experiments have done so. Caetano and Church (2009) found nose-poke responses and a 0.5-s presentation of a house light to function similarly as time markers to control responding during intervals to food for rats. They used a between-groups yoking procedure in which one group (response group) responded on a differential-reinforcement-of-low-rate (DRL) schedule of reinforcement. Rats in the second group (stimulus group) were randomly yoked to a rat in the response group such that a house light flashed for 0.5 s every time a response was made by the rat in the response group. Reinforcement was made available contingent on the first response 20 $\mathrm{s}$ after the last response by the rat in the response group. The use of the DRL schedule, however, constrained response rates in the response group while responding went unconstrained in the stimulus group. As a result, response rates were much higher in the stimulus group relative to the response group. This difference makes between-group comparisons difficult because most 
dependent measures evaluating temporal discrimination are derived from considerably more responding in the stimulus group; however, Caetano and Church found relative response rates across the interval (i.e., response patterning) to be similar in the two groups.

Fox and Kyonka (2013) used a within-subjects design to compare key pecks and keylight illuminations as time markers for pigeons. Four pigeons were exposed to typical FI schedules in which the onset of the interval was marked by the illumination of a key light, and to RIFI schedules in which the onset of the interval was marked by the first response on a trial (key peck on an illuminated key). In this procedure, response rates were not constrained under either schedule type as they were in Caetano and Church (2009). Fox and Kyonka found that absolute response rates were higher early in the RIFI schedules than the FI schedules and that inter-food intervals (IFIs) were longer and more variable in the RIFI schedules due to the responseinitiation requirement. However, response patterning based on normalized response-rate gradients, breakpoints, and ogive fits was similar in the two schedule types, suggesting equivalent temporal discrimination.

One of several potentially important procedural differences between the two experiments is that Fox and Kyonka (2013) allowed the rate of reinforcement to vary depending on pigeons' latencies to initiate intervals in the RIFI schedules. They did so to compare overall reinforcement rates between the two schedule types. As a result, reinforcement rates were lower and IFIs were longer and more variable in the RIFI schedules. If time between food deliveries was also controlling temporal discrimination, one might expect temporal discrimination to be disrupted in RIFI schedules. It may be that the pigeons relied on discriminating IFIs and did not necessarily use the illumination of the key light or the first response as the only time markers to discriminate when food would be available next. Therefore, equating reinforcement rates may affect 
comparisons of temporal discrimination between fixed intervals initiated by exteroceptive stimuli and fixed intervals initiated by responses. Such control was an important component of the first two experiments described below.

\section{Statement of the Problem}

Models of interval timing ${ }^{1}$ including Scalar Expectancy Theory (Gibbon, 1977), Behavioral Estimation Theory (Killeen \& Fetterman, 1988), and their contemporary descendants typically do not include the type of time marker that initiates the interval as a factor. In other words, with respect to the experimental questions being asked presently, they do not predict differences in temporal discrimination based on whether or not the fixed interval to food is initiated via a key peck or the illumination of a key light. Two previous studies have found exteroceptive stimuli and responses to control temporal discrimination similarly when they signaled the onset of a fixed interval to response-contingent food (Caetano \& Church, 2009; Fox \& Kyonka, 2013). The present series of experiments attempted to further delineate the potential importance of time marker dimension in interval timing-specifically, the experiments were designed to determine the efficacy of responses as time markers. If the time marker that initiates an interval affects temporal discrimination, then contemporary models of interval timing will necessarily need to include parameters that account for such differences.

Experiment 1 was designed to evaluate if controlling reinforcement rate and IFIs between FI and RIFI schedules affects temporal discrimination. To control reinforcement rate, the intertrial intervals (ITI) in FI conditions were yoked to the first-response latencies obtained in

\footnotetext{
${ }^{1}$ Throughout this document the term "timing” is meant to refer to patterns of behavior under the control of the temporal properties of some event. In the case of the three experiments presented below, timing refers to key pecking under the control of interval duration.
} 
corresponding RIFI conditions from the previous day. Experiment 2 was designed to evaluate temporal discrimination when occasionally food was withheld (i.e., on "no-food" or "peak trials;" Catania, 1970; Roberts, 1981). Pigeons were exposed to FI and RIFI peak procedures and additional measures of temporal discrimination were obtained and used to compare temporal discrimination in the two schedule types. In Experiment 2 reinforcement rates were controlled between the two schedule types using the same yoking procedure as in Experiment 1. Finally, Experiment 3 was designed to compare how a stimulus change associated with the first response during RIFI schedules affects behavior. To do so, pigeons were exposed to FI, RIFI, and Signaled-RIFI schedules of reinforcement.

\section{General Method}

\section{Subjects}

In each experiment, three White Carneau pigeons maintained at $85 \%$ of their free-feeding weight plus or minus $15 \mathrm{~g}$ through appropriate post-session feedings. The same three pigeons, numbered 301, 302, and 303, were used for Experiments 1 and 2. Three other pigeons, numbered 401, 402, and 403, were used for Experiment 3. Pigeons were housed individually in a vivarium with a 12-hr light/12-hr dark cycle and had continuous access to water.

\section{Apparatus}

Standard operant-conditioning chambers (25.5 cm deep x $32 \mathrm{~cm}$ wide x $33.5 \mathrm{~cm}$ high) enclosed in sound-attenuating boxes equipped with ventilation fans. Each chamber contained three response keys arranged $6 \mathrm{~cm}$ apart and $24 \mathrm{~cm}$ above the floor of the chamber. Response keys could be illuminated red, green or white. A grain hopper (5.5 cm high x $6 \mathrm{~cm}$ wide) was located below the middle response key and $5.5 \mathrm{~cm}$ from the floor. A house light was located at the top of the chamber on the wall opposite of the response keys. The grain hopper aperture was 
illuminated during reinforcer presentation and the hopper contained Purina Nutri-grain pigeon pellets. A force of approximately $0.15 \mathrm{~N}$ was required to register a response on any key. All experimental events were controlled through a computer and MED-PC $₫$ interface located in an adjacent room.

\section{Procedure}

For all three experiments, each condition lasted a fixed number of sessions (Perone, 1991; Sidman, 1960). Conditions in Experiments 1 and 3 lasted 20 sessions and data from the final six sessions of each condition were used in analyses. Conditions in Experiment 2 lasted 40 sessions and data from the final 12 sessions of each condition were used in analyses. Condition durations were chosen based on previous research in our laboratory that suggested normalized response-rate gradients stabilize within 10 sessions of exposure to each condition and there is no trend in overall session response rate from the same period. Twenty additional sessions in Experiment 2 were added to account for any potential disruptions the addition of the no-food trials (see below) may have had on responding. The final 12 sessions were used in the final analysis for Experiment 2 in order to include data from a greater number of no-food trials. During reinforcement (hopper presentation) all key lights and the house light were extinguished and the hopper light was illuminated. During inter-trial intervals (ITIs) the house light was illuminated, and during all trials it was extinguished. Although complete counterbalancing was not possible because three pigeons were used in each experiment, the pigeons were exposed to experimental conditions in different orders.

\section{Training}

Pigeons had different experimental histories. In an attempt to control for those histories and ensure all pigeons had sufficient experience with interval schedules, all pigeons experienced 
20 sessions of FI 15-s schedule training prior to the start of the experiments. Since the same pigeons were used in Experiments 1 and 2, this training was not repeated between the two experiments. During a training trial the center key was illuminated either red or green pseudorandomly (no more than two consecutive trials with the same key color) and the first response after 15 s was reinforced. Each trial was followed by a variable-time (VT) 5-s ITI and presentation of the subsequent trial. Each session lasted for 40 trials or $60 \mathrm{~min}$, whichever occurred first.

\section{Experiment 1}

Experiment 1 was designed to evaluate whether performance in FI and RIFI schedules differed systematically when the overall rate of reinforcement in the two schedule types was equated with a yoking procedure. Fox and Kyonka (2013) found that temporal discrimination was similar in FI and RIFI schedules, despite longer and more variable IFIs in the RIFI schedules that resulted in significantly higher overall reinforcement rates in the FI schedules. However, it was difficult to discern the role that food delivery was playing in temporal discrimination. A within-subject multiple-schedule yoking procedure was used in Experiment 1 to equate overall rates of reinforcement between the FI and RIFI schedules. In one component of the multiple schedule, responding was reinforced on an RIFI schedule with VT 5-s ITIs. In the other component responding was reinforced on an FI schedule, however, the ITI duration was yoked to the first-response latencies in the RIFI component from the previous day.

Previous research suggests that reinforcer delivery may be a more salient time marker than the onset of other stimuli (Freestone \& Church, 2010), and that IFIs control temporal discrimination (e.g., Higa, Wynne, \& Staddon, 1991; Wynne \& Staddon, 1988) and firstresponse latency (Rutter, 1990). It is possible that equating reinforcement rate in the manner 
proposed will alter performance in one or both of the schedule types—suggesting the pigeons are discriminating IFIs and not necessarily the time from stimulus onset (FI) or first response (RIFI) to food.

\section{Procedure}

A multiple-schedule arrangement was used in Experiment 1. Each session was divided into two components, each lasting 30 min or 20 trials, whichever came first. Only Pigeon 303 reached the maximum component duration. It occurred 12 times total, in the RIFI 30-s schedule each time, and in only one component used in data analysis. Each component was designated by either a red or green key light, and the order in which the components were presented on a daily basis was pseudorandom with the constraints that a component could not be presented first on more than two consecutive days and each component was presented first an equal number of times in a condition.

During one component, key pecks were reinforced with access to food on an RIFI schedule. On an individual trial, the center key was illuminated either red or green. The first response started the fixed interval timing down to reinforcer availability and the first response after the interval elapsed resulted in 5-s access to food. Reinforcement was followed by a VT 5-s ITI and the presentation of the subsequent trial. Pigeons 301 and 303 were exposed to the 15-s schedules first, followed by the 30-s schedules. The order was reversed for Pigeon 302.

During the other component, responding was reinforced on an FI schedule. In each condition, the fixed-interval duration was the same as in the corresponding RIFI component (15 or $30 \mathrm{~s}$ ); however, the ITI between reinforcer delivery and the illumination of the key light to initiate the subsequent FI on each trial was yoked to first-response latencies in the RIFI component from the previous day. First-response latencies are the times from key light 
illumination to the first response on individual trials. In RIFI schedules, this response initiated the interval to food. The first response had no programmed consequence in FI schedules—unless it occurred after the interval elapsed, in which case it resulted in access to food. During RIFI trials, the time from the end of reinforcement to the first response on the subsequent trial was recorded for all trials (i.e., VT 5-s ITI + first-response latency). These times then became the ITIs for the FI schedule component the following day. Each new FI trial began after the yoked ITI elapsed. For example, if the first-response latency from the first RIFI trial on a Tuesday was $8 \mathrm{~s}$ after a 3-s ITI, then the ITI for the first FI trial on the following Wednesday was $11 \mathrm{~s}$. During Session 1 for each condition, because there were no data from a previous RIFI component to yoke, VT 5-s ITIs were used in the FI component.

It is noteworthy that the environment during this yoked delay in the FI component was not equivalent to the environment prior to the first response in the RIFI component. Prior to the first response in the RIFI component, the house light was illuminated during the ITI, but then was extinguished when the trial began and the key light was illuminated. In the FI component the house light remained illuminated throughout the yoked ITI and the key light was not illuminated prior to interval onset. After the yoked ITI elapsed in FI components, the center key was illuminated either red or green-initiating the interval. For each pigeon, a single key color was always associated with one of the two schedule types. The first response after the interval elapsed resulted in 5-s access to food. The two components were separated by a 30-s blackout during which all lights were extinguished. The second component immediately followed the blackout.

\section{Results}


Figure 1 shows the mean number of reinforcers obtained per minute for each pigeon in each condition. Reinforcement rates were calculated by dividing the total number of reinforcers obtained per component by the total time spent in the component including ITIs and food-hopper presentations. Reinforcement rates for the last six components of a condition were calculated separately and then averaged. The mean number of reinforcers obtained per minute in the FI and RIFI 15-s schedules by the three pigeons were $1.70(S E M=0.40)$ and $1.74(S E M=0.30)$, respectively. The mean number of reinforcers obtained per minute in the FI and RIFI 30-s schedules were $1.17(S E M=0.14)$ and $1.16(S E M=0.15)$, respectively. Generally, the reinforcement rates in the FI and RIFI schedules were equivalent across pigeons and conditions_-an indication that the yoking procedure was successful.

Table 1 shows the median first-response latencies for each pigeon in each condition with each corresponding interquartile range (IQR) and range. Medians are reported because means tended to be skewed by outliers. Median first-response latencies were shorter in FI than RIFI conditions for all pigeons at both intervals. A Related-Samples Wilcoxon Signed-Rank test on median first-response latencies indicated relatively long median first-response latencies occurred more frequently in the RIFI schedules $(p<.05)$. (For details of statistical tests see Appendix A.)

Figure 2 shows the proportion of first-response latencies that occurred in bins equal to $10 \%$ of the corresponding interval duration (e.g., a 30-s interval is divided into 10 bins equal to 3 s each). Consistent with the longer median first-response latencies shown in Table 1, there was a systematically greater proportion of relatively long first-response latencies in the RIFI schedules across pigeons and conditions, although the effect was small. In the 15-s interval conditions, $56 \%, 74 \%$, and $66 \%$ of first-response latencies in the RIFI schedule exceeded the median firstresponse latency in the FI schedule for Pigeons 301, 302, and 303, respectively. In the 30-s 
interval conditions, 68\%, 63\%, and 53\% of first-response latencies in the RIFI schedule exceeded the median first-response latency in the FI schedule for Pigeons 301, 302, and 303, respectively. Kolmogorov-Smirnov (KS) tests were conducted to confirm quantitatively the differences in FI and RIFI first-response latency distributions observed. The KS test is a nonparametric test that makes no assumptions about the distribution of the data. In six of six cases (three pigeons x two intervals), the KS test showed the FI and RIFI first-response latency distributions were significantly different (all $p s<.05)$.

Figure 3 shows responses per minute as a function of time (s) since stimulus onset (FI) or first response (RIFI) for each pigeon in each condition. These response-rate gradients show how response rate changed as time to food decreased. To generate the response-rate gradients, intervals were divided into bins equal to $10 \%$ of the corresponding interval and responses per minute were calculated for each bin. Response rates increased as time to food decreased in both schedule types. The primary difference in the response-rate gradients for the two schedule types was that response rates early in the interval were higher in the RIFI schedules than the corresponding FI schedules across pigeons and conditions. Aggregated across pigeons and interval durations, absolute response rates during the first half of RIFI schedules were 199.06\% of rates during the first half of FI schedules. During the second half of the FI and RIFI schedules response rates were nearly equivalent-response rates in the FI schedules were $102 \%$ of rates in the RIFI schedules. Visual inspection of raster plots (Appendix B Figure B1) confirmed that in individual trials of the FI schedules there were fewer responses early in the interval compared to corresponding RIFI schedules.

Although absolute response rates at the start of intervals were higher in RIFI than FI schedules (Figure 3), visual inspection of responding on individual trials indicated that 
responding in both schedule types could be characterized as low-high in nature: a relatively low rate of responding early in the interval, followed by a change at a breakpoint to a relatively high rate of responding until food was delivered. Breakpoint locations are individual-trial measures of temporal discrimination that take into account all the responses recorded during a trial, instead of simply comparing first-response latencies, which represent just one response on a trial.

Breakpoints (Figure 4) were calculated by running an exhaustive search for the time of the response $\left(t_{1}\right)$ in each trial that maximized the following equation (Guilhardi \& Church, 2005):

$$
A=t_{1}\left(r-r_{1}\right)+t_{2}\left(r_{2}-r\right)
$$

where $t_{1}$ is the duration from interval onset to breakpoint, $t_{2}$ is the duration from breakpoint to food delivery, $r_{1}$ is the response rate during $t_{1}, r_{2}$ is the response rate during $t_{2}$, and $r$ is the mean response rate in the trial. Trials in which three or fewer responses occurred or the response rate before the breakpoint was higher than the response rate after the breakpoint were excluded from the analysis. A Repeated-Measures Analysis of Variance (RM ANOVA) on the number of trials excluded from the analysis with schedule type and interval duration as factors revealed no significant differences (all $p s>.05$ ). A significantly greater number of trials were not excluded from either schedule type.

Mean breakpoints were later in the FI schedules for Pigeons 302 and 303: 0.32 and 0.45 s later in the FI 15-s schedule than the RIFI 15-s schedule and 1.26 and 0.58 s later in the FI 30-s schedule than the RIFI 30-s schedule, respectively. Breakpoints were earlier in the FI schedules for Pigeon 301: 0.84 s earlier in the FI 15-s schedule than the RIFI 15-s schedule and 1.39 s earlier in the FI 30-s schedule than the RIFI 30-s schedule. A RM ANOVA on breakpoint with schedule type and interval duration as factors indicated a significant effect of interval duration ( $p$ $<$.05), but not of schedule type or the schedule type $\mathrm{x}$ interval duration interaction. Breakpoints 
were higher in the 30-s schedules, but there was no significant difference between the FI and RIFI schedules.

The functional relation between response rate and time since trial onset (Figure 3) may reveal differences not detected by comparing single-trial measures such as first-response latency and breakpoint. However, to compare changes in response rates as time to food decreased (i.e., response patterns), it is necessary to control for differences in absolute response rates obtained in the two schedule types. Normalizing the gradients from Figure 3 is one way to accomplish this. To calculate normalized response rates, each interval was divided into 10 bins equal to $10 \%$ of the corresponding interval. The minimum response rate observed across the 10 bins in the interval was then subtracted from the response rate in each bin. The remaining value in each bin was then divided by the maximum response rate observed across bins in the interval. This adjustment ensured that the normalized response rate curves for all the gradients in both schedules ranged from 0 (the normalized minimum response rate) to 1 (the normalized maximum response rate). By normalizing the response-rate gradients the general pattern of changes in response rate across the intervals in the two schedule types can be compared while controlling for the differences in absolute response rate that were observed. Figure 5 shows normalized response rate as a function of normalized time for each pigeon in each condition.

The normalized response-rate gradients permit visual inspection of differences between the FI and RIFI schedules, but for a quantitative characterization of the functional relation between response rate and time since the start of a fixed interval, an ogive function (Guilhardi \& Church, 2005) was fitted to the normalized response-rate gradients using Equation 2:

$$
y=\frac{1}{1+e^{-(x-a) / b}} .
$$


Parameter $a$ determines the center of the function (the time in which the response rate reached half of its maximum), and parameter $b$ is the scale or slope of the function. Larger estimates of $b$ indicate steeper slopes and therefore more abrupt changes in the response gradients. More abrupt changes occur when the range of obtained breakpoints from individual trials is smaller.

For each pigeon and condition, parameters $a$ and $b$ of Equation 2 were fitted to individual-pigeon normalized response-rate gradients to maximize variance accounted for (VAC) using a nonlinear optimization algorithm (Microsoft Excel Solver). Higher values of parameter $a$ and lower values of parameter $b$ are typically indicative of better temporal control. The best fitting line from the model is shown as solid (FI) and dashed (RIFI) lines on the normalized response-rate gradients in Figure 5.

For 11 out of 12 of the ogive fits, VAC was .97 or greater. The exception was the fit for Pigeon 302 in the RIFI 15-s condition (VAC = .65). This relatively poor fit for Pigeon 302 was due to a decrease in response rate near the end of the interval (see Figure 3 and Figure 5). Parameter estimates from Equation 2 are listed in Table 2. Separate RM ANOVA on the $a$ and $b$ parameter estimates with schedule type and interval duration as factors revealed no statistically significant differences (all ps $>$.05). Across pigeons there were no systematic differences between FI and RIFI conditions based on the centers and slopes of the ogive fits, which suggests similar response patterning in the two schedule types.

\section{Discussion}

In Experiment 1, three pigeons were exposed to FI and RIFI 15- and 30-s schedules of reinforcement in a multiple-schedule arrangement. In order to equate reinforcement rates in the two schedule types, the ITIs in the FI schedule were yoked to the first-response latencies from the previous day’s RIFI schedule. VAC estimates above .97 suggest Equation 2 provided an 
accurate quantitative characterization of normalized response-rate gradients for both schedule types, which means meaningful comparisons of ogive parameters can be made between the two schedule types. Breakpoints, ogive model fits to normalized response-rate gradients, and visual inspection of the normalized response-rate gradients indicated no systematic difference in temporal discrimination between the two schedule types: temporal discrimination was better (e.g., estimates for parameter $a$ in Equation 2 where higher) in the RIFI schedule for Pigeon 301, better in the FI schedule for Pigeon 302, and similar in the RIFI and FI schedules for Pigeon 303. The additional response requirement to initiate the interval in RIFI conditions- the response time marker — did not have a consistent effect on response pattern or temporal discrimination across pigeons. This was true despite higher absolute response rates early in the RIFI schedules and equivalent rates of reinforcement in the FI and RIFI schedules.

Fox and Kyonka (2013) exposed pigeons to FI and RIFI schedules and allowed reinforcement rates to vary in the two schedule types. As a result of the response-initiation requirement in the RIFI schedules, IFIs were longer and more variable and reinforcement rates were lower in the RIFI schedules. While Fox and Kyonka did not find differences in temporal discrimination between the schedule types, it was difficult to discern the extent to which the pigeons were using food delivery as a time marker in addition to stimulus onset (FI) and first response (RIFI) to time the delivery of future food. It is feasible that temporal discrimination was disrupted in the RIFI schedules because of longer and more variable IFIs relative to the FI schedules. Previous research suggests that IFIs play an important role in determining temporal control of behavior (e.g., Higa, Wynne, \& Staddon, 1991; Rutter, 1990; Wynne \& Staddon, 1988) and that food delivery may be a more salient time marker than other stimuli (Freestone \& Church, 2010). In other words, food delivery may be the relevant time marker for controlling 
future behavior related to food procurement. If food delivery is the time marker controlling responding in FI and RIFI schedules, and the intervals between food deliveries in FI schedules are shorter and more consistent than in RIFI schedules of the same duration, as they were in Fox and Kyonka (2013), it might be predicted that temporal discrimination would be disrupted in the RIFI schedule.

By controlling reinforcement rate via the yoking procedure employed in Experiment 1, the role of food delivery as a time marker was rendered equivalent in the two schedule types-if the pigeons were using food delivery as a marker to time the next food delivery it would not be a better predictor in one of the schedule types. In Experiment 1, temporal discrimination was not systematically different depending on the type of time marker employed. This is an indication that the time markers functioned similarly and supports previous research finding responses and stimuli to be equally efficacious time markers (Caetano \& Church, 2009; Fox \& Kyonka, 2013).

In addition, differences in absolute response rates obtained between FI and RIFI schedules were consistent with previous research (Fox \& Kyonka, 2013). Specifically, higher response rates early in the RIFI schedules than corresponding FI schedules were observed. Firstresponse latencies obtained in Experiment 1were also consistent with Fox and Kyonka (2013)—a relatively greater proportion of long first-response latencies in the RIFI schedule across pigeons. These findings suggest that the differences in performance between the two schedule types observed by Fox and Kyonka were not an artifact of longer more variable IFIs in the RIFI schedule, but of the response-initiation requirement in the RIFI schedule. Rutter (1990) suggested that first-response latencies in FI and RIFI schedules are controlled by IFI duration, however, the generally longer first-response latencies observed in the RIFI schedules in Experiment 1 occurred independent of differences in IFIs. 
Generally, characterizations of FI and RIFI schedules in Experiment 1 were consistent with previous research employing one or both schedule types. Longer scheduled intervals generated longer first-response latencies under both schedule types and first-response latencies were longer in RIFI than FI schedules of the same interval duration (Chung \& Neuringer, 1967; Fox \& Kyonka, 2013; Lowe et al., 1974; Shull, 1970a; Weaver \& Branch, 2008). This is particularly interesting because earlier first-response latencies in RIFI schedules would result in higher rates of reinforcement. A similar effect is observed in fixed-ratio (FR) schedules, and Capehart, Eckerman, Guilkey, and Shull (1980) offer several reasons for thinking that control of first-response latencies in FR and RIFI schedules is similar. In addition, response-rate gradients aggregated from the last six sessions of each condition in Experiment 1 were ogival in FI (Branch \& Gollub, 1974) and RIFI (Fox \& Kyonka, 2013) conditions and, responding on individual trials could be characterized as taking a “low-high” pattern in FI (Schneider, 1969) and RIFI (Fox \& Kyonka, 2013) schedules. The results of Experiment 1 indicate that the equivalence of responses and exteroceptive stimuli as time markers obtained in previous research was not a result of procedural idiosyncrasies or differences in reinforcement rates. They add to the evidence that time marker dimension may not affect temporal discrimination.

\section{Experiment 2}

One prevailing issue across all three previous experiments (Caetano \& Church, 2009; Fox \& Kyonka, 2013; Experiment 1) evaluating responses and exteroceptive stimuli as time markers is that responding was always interrupted by food delivery. It is difficult to evaluate temporal discrimination in these experimental arrangements because the animal may simply start responding on a trial and continue to respond until food is delivered. The increase in response rate as time to food decreases observed in these experiments suggests anticipation of food 
delivery; however, it does not necessarily depend on the animal having learned the time of food delivery. In order to evaluate the time in which the animal has learned to expect food delivery, the animal must be tested in the absence of food delivery. One way to conduct such a test is to employ a "peak procedure.” Peak procedures are modified FI procedures in which occasional trials are no-food trials or “empty” trials (Catania, 1970; Roberts, 1981). No-food trials last longer than food trials (standard FIs), they end without the delivery of reinforcement. On no-food trials it is possible to obtain additional measures of temporal discrimination, including a response-rate gradient after the usual time of reinforcer delivery and start and stop times for responding on individual trials (Church, Meck, \& Gibbon, 1994). Start times are the point before food delivery when the animal starts responding (analogous to breakpoints), and stop times are the point after typical food delivery when the animal stops responding. Experiment 2 included FI and RIFI no-food trials in a multiple schedule arrangement similar to that used in Experiment 1.

Responding on no-food trials provides opportunities to obtain additional measures of temporal discrimination and may provide a clearer picture of potential differences in temporal discrimination when an interval is initiated with a stimulus (FI) or a response (RIFI). In some cases, stop times and the response-rate gradients obtained after typical food delivery may be more sensitive measures of temporal discrimination than breakpoints and response-rate gradients obtained before typical food delivery (Kyonka \& Grace, 2010). If accuracy is affected by the time marker in FI and RIFI schedules, response-rate gradients, the time of peak response rate, and start and stop times will be shifted to the left (earlier) or right (later), relative to the other schedule type. The top graph in Figure 6 illustrates a hypothetical example of differences in timing accuracy but equivalent timing precision in two response-rate gradients from no-food trials. If timing precision is affected by the time markers in FI and RIFI schedules, start and stop 
times will be different and peak curves will have different widths, but the time of peak response rate will be similar. The bottom graph in Figure 6 illustrates a hypothetical example of differences in timing precision but equivalent timing accuracy in two response-rate gradients from no-food trials.

\section{Procedure}

A multiple-schedule arrangement was used in Experiment 2, similar to the one used in Experiment 1. Each session was divided into two components_-an FI and an RIFI componentand each lasted 45 min or 25 trials, whichever came first. No components were terminated as a result of the 45-min maximum. Each component was associated with either a red or green key light, and the order in which the components were presented on a daily basis was pseudorandom with the constraints that a component could not be presented first on more than two consecutive days and each component was presented first an equal number of times in a condition.

Regular FI and RIFI trials were the same as in Experiment 1. No-food trials started the same as regular FI and RIFI trials; that is, the only discriminative signal distinguishing no-food trials from food trials occurred after the interval elapsed (i.e., the passage of time). Each no-food trial lasted three times as long as the scheduled interval. For example, in the RIFI 30-s conditions, a no-food trial lasted until 90 s after the first response. Responses in no-food trials never produced food. The first response in RIFI no-food trials initiated the no-food interval timing. After the no-food trial timer elapsed, the key light was extinguished and the ITI and subsequent trial followed.

One of every five trials was a no-food trial. The location of no-food trials within blocks of five intervals was determined randomly, imposing the constraint that no more than two nofood trials could occur consecutively during any session. In each component, 20 trials were food 
trials and five trials were no-food trials, for a total of 40 food trials and 10 no-food trials per session.

Reinforcement rates in the FI and RIFI components were controlled for using the yoking procedure described in Experiment 1: ITIs in the FI component were yoked to the VT 5-s ITI plus the first-response latency in each trial from the previous day’s RIFI component.

\section{Results}

Figure 7 shows the mean number of reinforcers obtained per minute for each pigeon in each condition. Reinforcement rates were obtained by dividing the total number of reinforcers obtained per component by the total time spent in the component including ITIs and food-hopper presentations. Reinforcement rates for the last six components of a condition were calculated separately and then averaged. The mean number of reinforcers obtained per minute by the three pigeons in the FI and RIFI 15-s schedules were $1.28(S E M=0.09)$ and $1.28(S E M=0.12)$, respectively. The mean number of reinforcers obtained per minute in the FI and RIFI 30-s schedules were $0.74(S E M=0.10)$ and $0.74(S E M=0.09)$, respectively. As in Experiment 1 , the yoking procedure was successful in equalizing reinforcement rates in the FI and RIFI schedules across pigeons and conditions.

All results related to Experiment 2 reported from this point forward are based on analyses of responding that occurred during no-food trials. Table 3 shows the median first-response latencies for each pigeon in each condition along with each interquartile range (IQR) and range. Median first-response latencies were shorter in FI than RIFI conditions, with Pigeon 301 in the 30-s schedules as an exception. A Related-Samples Wilcoxon Signed-Rank test on median firstresponse latencies indicated relatively long median first-response latencies occurred more frequently in the RIFI schedules $(p<.05)$. 
Figure 8 shows the proportion of first-response latencies that occurred in bins equal to $10 \%$ of the corresponding interval. As in Experiment 1, there was a consistently greater proportion of relatively long first-response latencies in the RIFI schedule across pigeons and conditions. In the 15-s interval conditions, 72\%, 93\%, and 53\% of first-response latencies in the RIFI schedule exceeded the median first-response latency in the FI schedule for Pigeons 301, 302, and 303, respectively. In the 30-s interval conditions, 45\%, 95\%, and 73\% of first-response latencies in the RIFI schedule exceeded the median first-response latency in the FI schedule for Pigeons 301, 302, and 303, respectively. KS tests were conducted to confirm quantitatively the differences in FI and RIFI first-response latency distributions observed. In five of six cases, the KS test showed the FI and RIFI first-response latency distributions were significantly different (all $p s<.01)$. The exception was Pigeon 301 in the 30 -s schedules $(p=.16)$.

Figure 9 shows responses per minute as a function of time (s) since stimulus onset (FI) or first response (RIFI) for each pigeon in each condition. These gradients show how responding changed as the time of food delivery on food trials came and went. To calculate the response-rate gradients, no-food intervals were divided into bins equal to $10 \%$ of the corresponding interval and responses per minute were calculated for each bin. In both schedule types, response rates in the 15- and 30-s intervals increased as time to typical food delivery decreased, peaked near the time of typical food delivery, and then decreased. Consistent with the “ramped”-Gaussian function reported elsewhere on peak trials (e.g., Kirkpatrick, Miller, Betti, \& Wasserman, 1996), responding began to increase toward the end of both the 15- and 30-s no-food intervals (the "tail” on the response-rate gradients). Aggregated across pigeons and interval durations, absolute response rates during the first half of RIFI schedules were $188.24 \%$ of rates during the first half 
of FI schedules. During the second half of the FI and RIFI schedules response rates were nearly equivalent-response rates in the RIFI schedules were $103 \%$ of rates in the FI schedules.

There are some individual differences worth noting in Figure 9 because although responding on FI no-food trials was relatively consistent across pigeons, responding in RIFI nofood trials varied. Response-rate gradients for Pigeon 301 in the two schedule types were nearly identical despite higher absolute rates in the RIFI schedules. The RIFI response-rate gradients for Pigeon 302 increased to the maximum rate earlier than the FI response-rate gradients, but the decline in response rate occurred at approximately the same point in the two schedule types. The opposite was true for Pigeon 303-the RIFI response-rate gradients for Pigeon 303 increased to the maximum rate at approximately the same time as the FI response-rate gradients, but declined later. In addition, the function for Pigeon 303 in the RIFI 30-s schedule is noticeably flatter than the gradients for the other conditions and pigeons. Visual inspection of raster plots (Appendix B Figure B2) confirmed these differences in responding in FI and RIFI no-food trials.

As in Experiment 1, response-rate gradients were normalized to permit comparisons of changes in response rate (i.e., response pattern) in the two schedule types. Figure 10 shows normalized response rate as a function of normalized time (in bins equal to $10 \%$ of the corresponding interval) for each pigeon in FI conditions (top graph) and RIFI conditions (bottom graph). In the top graph of Figure 10, the FI normalized response-rate gradients are similar across pigeons and interval durations. The normalized ramped-Gaussian functions peaked at a group mean of $0.91(S E M=0.14)$ in the FI 15-s schedule and at $1(S E M=0.1)$ in the FI 30-s schedule. In the bottom graph of Figure 10, there is more variability in the RIFI normalized response-rate gradients. The normalized ramped-Gaussian functions peaked at a group mean of $1.02(S E M=0.3)$ in the RIFI 15-s schedule and at $0.9(S E M=0.3)$ in the RIFI 30-s schedule. 
While all the normalized RIFI functions could be described as "ramped” Gaussian functions with peaks at the approximate time of food delivery on food trials, the visual width of the peak is wider than in the FI schedules and the functions do not superimpose as consistently as in the FI schedules.

In order to more closely examine performance in the FI and RIFI no-food trials, an individual trial-based analysis was performed. Aggregating response rate data across trials as described above gives the indication that responding increased and decreased gradually on individual trials as the time of typical food delivery came and went, respectively. However, that is an inaccurate depiction of behavior on individual trials. Responding on individual trials is better characterized as being "low-high-low" in nature. That is, responding on any given no-food trial in FI and RIFI schedules typically started at low rate, increased at some breakpoint to a high rate of responding (the "start" time), remained in this "high-rate state” until a second breakpoint (the "stop" time), at which time responding decreased to a low rate. The accelerating "tail" at the end of each no-food trial is included in this second low-rate period. To identify these high-rate periods a low-high-low analysis was conducted on each no-food trial (Church, Meck, \& Gibbon, 1994). This involved an exhaustive search for the best fitting model that maximized the value of the index:

$$
A=t_{\mathrm{L} 1}\left(r-r_{\mathrm{L} 1}\right)+t_{\mathrm{H}}\left(r_{\mathrm{H}}-r\right)+t_{\mathrm{L} 2}\left(r-r_{\mathrm{L} 2}\right),
$$

where $r$ was the overall mean response rate on a trial, $r_{\mathrm{L} 1}, r_{\mathrm{H}}$ and $r_{\mathrm{L} 2}$ were the response rates in the first low, the high, and the second low states, respectively, and $t_{\mathrm{L} 1}, t_{\mathrm{H}}$, and $t_{\mathrm{L} 2}$ were the durations of those respective states. The sum of the start time and half of the high-rate state duration was considered the middle time - the midpoint of the start and stop time. The middle time is a singletrial alternative measure to the time of peak response rate from the aggregated response-rate 
gradients (Figure 10). Equation 3 was used to calculate the start and stop times that maximized the difference between the first and second low-rate states and the high-rate state between them. Start and stop times are individual-trial measures of temporal discrimination that take into account all the responses recorded during a trial. Trials in which the start time occurred after the programmed interval duration, the stop time occurred before programmed interval duration, or the stop time occurred within the last second of the no-food trial (i.e., no clear stop identified) were excluded from the analysis. A RM ANOVA on the number of trials excluded from the analysis with schedule type and interval duration as factors revealed no significant differences (all ps $>$.05). A significantly greater number of trials were not excluded from either schedule type.

Figure 11 shows mean start, middle, and stop times obtained using Equation 3 for the FI and RIFI 15- and 30-s schedules. For all pigeons and all conditions, the middle time was located near the time of typical food delivery. A RM ANOVA on middle times with schedule type and interval duration as factors indicated a significant effect of interval duration $(p<.01)$, but no significant effect of schedule type or the schedule type x interval duration interaction. Middle times were significantly later in the 30-s schedules, but the schedule type did not produce significant differences.

In five of six comparisons (three pigeons x two interval durations) the RIFI mean highstate duration was longer than the corresponding FI high-state duration. For Pigeons 302 and 303 the RIFI 15-s high-state duration was 5.11 and 4.34 s longer, respectively, than the FI 15-s highstate duration; and for Pigeons 301, 302, 303 the RIFI 30-s high-state duration was 1.44, 10.14, and 5.14 s longer, respectively, than the FI 30-s high-state duration. A Related-Samples 
Wilcoxon Signed-Rank test on mean high-state duration indicated relatively long high-rate state durations occurred more frequently in RIFI than FI schedules $(p<.05)$.

Dividing the high-state duration by the corresponding middle time yields a standardized index for comparing high-state duration across pigeons and interval durations (i.e., how long on average did the high-state duration last relative to the timed interval). Higher values of this index indicate less precise timing. Figure 12 shows the mean of this index for each pigeon in each condition. For Pigeons 302 and 303 the mean of this index was 156\% and 114\% higher in the RIFI than the FI 15 -s schedule, and $137 \%$ and $114 \%$ higher in the RIFI than the FI 30 -s schedule, respectively_ an indication that for these two pigeons timing was less precise in the RIFI schedules than the FI schedules. For Pigeon 301 the mean of this index was $118 \%$ higher in the FI than the RIFI 15-s schedule and equivalent in the FI than RIFI 30-s condition-an indication that for this pigeon timing was more precise in the FI 15-s than the RIFI 15-s, but about the same in the FI and RIFI 30-s schedules. KS tests comparing the distributions of the index in FI and RIFI schedules aggregated across all pigeons indicated a significant difference $(p<.01)$. Specifically, the 95\% confidence interval for the index in the FI schedules was 1.06-1.12 compared to 1.24-1.33 in the RIFI schedules. This analysis suggests that timing was less precise in the RIFI schedule than the FI schedule.

\section{Discussion}

In Experiment 2, three pigeons were exposed to FI and RIFI 15- and 30-s schedules of reinforcement in a multiple-schedule arrangement. No-food trials were included during both FI and RIFI components in order to assess timing in the absence of food delivery. In order to equate reinforcement rates in the two schedule types, the ITIs in the FI schedule were yoked to the firstresponse latencies from the previous day’s RIFI schedule. This yoking rendered food delivery as 
a time marker equivalent in the two schedule types. Normalized response-rate gradients on nofood trials indicated more between-subject variability and a generally wider peak in the RIFI schedules, though, the gradients in both schedule types peaked at the approximate time of typical food delivery. The low-high-low analysis of responding on individual trials indicated similar middle times in the two schedule types, but longer high-state durations in the RIFI schedules than FI schedules, especially for Pigeons 302 and 303. In addition, a standardized measure of timing precision indicated less precise timing in the RIFI schedules than the FI schedules. Together these results suggest that while timing accuracy was unaffected by the type of time marker employed, timing precision was reduced in the RIFI schedules when a response initiated the interval to food.

In previous research (Fox \& Kyonka, 2013) and Experiment 1, temporal discrimination was similar in FI and RIFI schedules with respect to breakpoints and ogive fits to normalized response-rate gradients. However, the experimental methods employed in Experiment 2 allowed for a more sensitive assessment of temporal discrimination in FI and RIFI schedules. Under these conditions, accuracy was similar in the two schedule types, but timing precision was reduced in the RIFI schedules. This reduction in precision was not detectable in previous research because all trials ended with food delivery. In Experiment 2 the reductions in timing precision were sometimes only detectable when responding was observed after the time of typical food delivery. The results of Experiment 2 suggest that when an organism must rely solely on its own past behavior to time future behavior the precision with which the future behavior will occur may be disrupted relative to if the future behavior was being timed from an exteroceptive stimulus change. 
Consistent with previous research (Fox \& Kyonka, 2013) and Experiment 1, response rates early in the RIFI schedules were higher than in the corresponding FI schedules in Experiment 2. First-response latencies obtained in Experiment 2 were also consistent with Fox and Kyonka (2013) and Experiment 1—a relatively greater proportion of long first-response latencies in the RIFI schedules across pigeons. The results from Experiment 2 provide additional evidence that the higher absolute response rates observed early in RIFI schedules and a relatively greater proportion of long first-response latencies observed in RIFI schedules relative to FI schedules are not an artifact of the longer IFIs and lower reinforcement rates observed by Fox and Kyonka (2013) but of the response-initiating requirement in the RIFI schedule.

The accuracy and precision of timing have been shown to be affected by a variety of variables. For example, reducing motivation by reducing food deprivation (Balci, Ludvig, \& Brunner, 2010; Plowright, Church, Behnke, and Silverman, 2000), by manipulating reinforcer magnitude (Galtress \& Kirpatrick, 2009; Ward \& Odum, 2006, 2007), or by manipulating dopamine levels (Balci, Ludvig, Abner, Zhuang, Poon, \& Brunner, 2010; Ward, Kellendonk, Simpson, Lipotova, Drew, Fairhurst, Kandel, \& Balsam, 2009) can result in altered timing accuracy and lower timing precision. A reduction in attention via some disruptor can also result in altered timing accuracy and reduced timing precision (e.g., Buhusi \& Meck 2006a, 2006b; Ward \& Odum, 2007). Exposing humans to an aversive event results in an overestimation of time (e.g., Droit-Volet \& Meck, 2007; Langer, Wapner, \& Werner, 1961; Watts \& Sharrock, 1984). The administration of drugs can also influence timing accuracy and precision. In particular, dopamine agonists tend to lead to an overestimation of time and dopamine antagonists tend to lead to an underestimation of time (e.g., Body, Cheung, Valencia-Torres, Olarte-Sanchez, 
Fone, Bradshaw, \& Szabadi, 2013; Cheung, Bezzina, Hampson, Body, Fone, Bradshaw, \& Szabadi, 2007; Matell, Bateson, \& Meck, 2006; Matell, King, \& Meck, 2004).

By contrast, very little research has evaluated how interval timing is affected by differences in time-marker dimension (Caetano \& Church, 2009; Fox \& Kyonka, 2013). The results of Experiment 2 are the first to show that interval timing precision may be reduced when a response marks the start of an interval compared to the onset of a light. However, it is not the first experiment to show that manipulating the physical dimensions of stimuli can produce differences in timing performance. For example, studies have shown that auditory stimuli are estimated as longer than visual stimuli of the same duration (e.g., Goldstone \& Lhamon, 1974; Penny, Gibbon, \& Meck, 2000); bright lights are estimated as longer in duration than dim lights of the same duration (Kraemer, Brown, \& Randall, 1995); and filled intervals (constant tone) are estimated as longer in duration than empty intervals (start and end of intervals demarcated by a brief tone) of the same duration (Santi, Miki, \& Hornyak, 2005).

It is perhaps surprising that when the time marker was a response, timing was less precise than when the time marker was an exteroceptive stimulus because timing accuracy and precision are at least in part affected by variables related to attention (see above). Therefore, it might be predicted that timing precision would be greater in RIFI schedules than FI schedules because attending to the start of the interval is required in RIFI but not FI schedules. In FI schedules, attending to the onset of the interval seems less likely to occur on every trial—the pigeon may be engaged in grooming, be turned away from the stimulus light, or engaged in another activity that blocks attending to stimulus onset in the FI schedule. Indeed, based on this rationale some experimental preparations require an organism to gaze at a specific location (monkeys; e.g., Lau 
\& Glimcher, 2005) or peck a key (pigeons; e.g., Vasconcelos \& Urcuioli, 2008) in order to initiate a trial. The results of Experiment 2 suggest this is at the very least a false assumption.

\section{Experiment 3}

In Experiments 1 and 2, key pecks and key-light illuminations were compared independently of one another as time markers. The objective of Experiment 3 was to assess effects of a time marker that combined a response and exteroceptive stimulus change. To do so, the behavior of three pigeons was compared in FI, RIFI, and Signaled-RIFI schedules of reinforcement. A Signaled-RIFI schedule is the same as an RIFI schedule, except that the interval-initiating response (first response on a trial) is required on a separate response key and is associated with a key-light color and location change. For example, on a trial the intervalinitiating response is required on a side key illuminated white, and results in the extinguishing of that key, the illumination of the center key red, and the start of the FI. As mentioned previously, RIFI schedules are tandem FR1-FI schedules. Accordingly, a Signaled RIFI is a chained FR1-FI schedule.

The purpose of Experiment 3 was to assess whether signaling the first response of an RIFI schedule affects responding relative to RIFI and FI schedules and to compare measures of temporal discrimination in all three schedule types within subject. Previous research comparing RIFI and FI schedules has found first-response latencies to be similar and positively related to the duration of the FI, but did not include additional dependent measures related to temporal discrimination (Rutter, 1990; Shull, 1970b).

It is possible that signaling the first response in RIFI schedules will increase the saliency of the first key peck (the key peck that initiates the interval) relative to other key pecks that occur during a trial (key pecks that either have no programmed consequence or are reinforced via food 
delivery). If so, responding in Signaled-RIFI schedules may be more similar to that observed in FI than RIFI schedules.

\section{Procedure}

All pigeons were exposed to FI, RIFI, and Signaled-RIFI 15- and 30-s schedules of reinforcement separately and in different orders across pigeons. On any given day, a pigeon only experienced one schedule type and did not experience another schedule type until both the 15and 30-s conditions of the current schedule type were experienced. RIFI and FI trials were arranged the same as in previous experiments, except that unlike in Experiments 1 and 2, reinforcement rates were free to vary between schedule types. In order to make comparisons between overall reinforcement rates in the schedule types, there was no yoking procedure in Experiment 3. Signaled-RIFI trials were the same as RIFI trials except the left or right key (pseudorandomly) was illuminated white upon trial initiation. The first response extinguished the

side key, lighted the center key red or green (red for Pigeons 301 and 303; green for Pigeon 302), and started the fixed-interval timing. The first response after the interval elapsed resulted in 5-s access to pellets. Sessions lasted 40 trials or 60 min, whichever occurred first. No sessions ended due to the 60-min maximum.

\section{Results}

Figure 13 shows the mean number of reinforcers obtained per minute for each pigeon in each condition. Reinforcement rates were obtained by dividing the total number of reinforcers obtained in a session by the total time spent in the session excluding ITIs and food-hopper presentations. Reinforcement rates for the last six sessions of a condition were calculated separately and then averaged. Reinforcement rates were calculated differently for Experiment 3 because ITI duration was constant across conditions, thus the relevant comparisons are between 
schedule types in Experiment 3 and not with reinforcement rates obtained in Experiments 1 or 2, which employed the yoking procedure. Reinforcement rates were highest in the FI schedules: near the maximum possible rate of four per minute under 15-s interval conditions and two per minute under 30-s interval conditions for all pigeons. Reinforcement rates in the two schedule types that required an interval-initiating response were lower, but in all cases reinforcement rates were higher in the Signaled-RIFI schedules than the corresponding RIFI schedules. The group mean reinforcement rate was 2.97 (SEM $=0.25$ ) reinforcers per minute in the RIFI 15-s schedule compared to $3.17(S E M=0.12)$ reinforcers per minute in the Signaled-RIFI 15-s schedule. Similarly, the group mean reinforcement rate was $1.35(S E M=0.24)$ reinforcers per minute in the RIFI 30-s schedule compared to 1.54 (SEM = 0.17) reinforcers per minute in the SignaledRIFI 30-s schedule. A RM ANOVA on reinforcement rates with schedule type and interval duration as factors indicated a significant effect of schedule type, interval duration, and a significant interaction $(p s<.05)$. Post-hoc paired samples $t$-tests indicated that reinforcement rates in the FI schedules for both interval durations were higher than rates in both the RIFI and Signaled-RIFI schedules $(p s<.05)$.

Table 4 shows median first-response latencies for each pigeon in each condition along with each interquartile range (IQR) and range. In Experiments 1 and 2, median first-response latencies were shorter in FI than RIFI schedules, but they were not systematically different in Experiment 3. Median first-response latencies in the Signaled-RIFI schedules were shorter than in both FI and RIFI schedules for all pigeons at both interval durations, with one exception: the median first-response latency for Pigeon 401 in the Signaled-RIFI 15-s schedule was $0.08 \mathrm{~s}$ longer than in the RIFI 15-s schedule. Separate Wilcoxon Signed-Rank Tests on median firstresponse latencies indicated no significant difference between FI and RIFI schedules or between 
RIFI and Signaled-RIFI schedules ( $p>.05$ ), but first-response latencies were statistically significantly more likely to be shorter in the Signaled-RIFI than FI schedules $(p<.05)$.

Figure 14 shows the proportion of first-response latencies that occurred in bins equal to $10 \%$ of the corresponding interval. Unlike in Experiment 1 and 2, the proportion of long firstresponse latencies was not greater in the RIFI compared to the FI schedules. In the 15-s interval conditions, $27 \%$, 35\%, and $24 \%$ of first-response latencies in the RIFI schedule exceeded the median first-response latency in the FI schedule for Pigeons 401, 402, and 403, respectively. In the 30 -s interval conditions, $48 \%, 64 \%$, and $83 \%$ of first-response latencies in the RIFI schedule exceeded the median first-response latency in the FI schedule for Pigeons 401, 402, and 403, respectively. However, first-response latencies exceeded the scheduled interval duration more often in the RIFI schedule than in the FI schedule. Across pigeons, the first-response latency exceeded the scheduled interval duration on only two trials in the FI schedules (Pigeon 403 in the FI 15-s schedule both times). By contrast, the first response latency exceeded the scheduled interval duration on 209 trials in the RIFI schedules-across interval durations this occurred once for Pigeon 401, 141 times for Pigeon 402, and 67 times for Pigeon 403.

One distinguishing feature of the frequency distributions in Figure 14 is the relatively greater proportion of first-responses that occurred early in the Signaled-RIFI schedule compared to the FI and RIFI schedules. This is especially relevant when comparing first-response latencies in the RIFI and Signaled-RIFI schedule because the only difference between the two schedules was the signaling of the initiating response. In the 15 -s interval conditions, $49 \%, 75 \%$, and $70 \%$ of first-response latencies in the Signaled-RIFI schedule were shorter than the median firstresponse latency in the RIFI schedule for Pigeons 401, 402, and 403, respectively. In the 30-s interval conditions, $75 \%, 73 \%$, and $96 \%$ of first-response latencies in the Signaled-RIFI schedule 
were shorter the median first-response latency in the RIFI schedule for Pigeons 401, 402, and 403, respectively. The signaling of the initiating response in the Signaled-RIFI schedules resulted in a shift to shorter first-response latencies compared to corresponding RIFI schedules. This resulted in the relatively higher reinforcement rates reported above.

KS tests were conducted to confirm quantitatively the differences between FI, RIFI, and Signaled-RIFI first-response latency distributions observed. For each pigeon at both interval durations the distribution from each schedule type was compared with the distributions from the other two schedule types (i.e., FI versus RIFI, FI versus Signaled-RIFI, RIFI versus SignaledRIFI; 18 comparisons total). The KS test showed the first-response latency distributions were significantly different for 16 of 18 comparisons (all $p s<.01$ ). The exceptions were Pigeon 401 between the RIFI and Signaled-RIFI 15-s schedule distributions ( $p=.17)$ and between the FI and RIFI 30-s schedule distributions $(p=.36)$.

Figure 15 shows responses per minute as a function of time (s) since stimulus onset (FI) or first response (RIFI and Signaled-RIFI) for each pigeon in each condition. These gradients show how responding changed as time to food decreased. To calculate response-rate gradients, intervals were divided into bins equal to $10 \%$ of the corresponding interval and responses per minute were calculated for each bin. Response rates increased as time to food decreased in all schedule types. As in previous experiments, response rates early in the interval were higher in the RIFI schedule than the FI schedule across pigeons and conditions. Aggregated across pigeons and interval durations, absolute response rates in the first half of RIFI schedules were $153.34 \%$ of rates in the first half of FI schedules. In the second half of the FI and RIFI schedules response rates were nearly equivalent—response rates in the RIFI schedules were $103 \%$ of rates in the FI schedules. 
Interestingly, based on visual inspection response-rate gradients in the Signaled-RIFI schedule were more similar to the FI gradients than the RIFI gradients, with the exception of the 15-s interval schedules for Pigeon 401. The signaling of the interval-initiating response in the Signaled-RIFI schedule resulted in lower response rates early in the intervals compared to response rates in the RIFI schedule. It should be noted, though, that the majority of the SignaledRIFI response-rate gradients are not exactly the same as the FI gradients, and in four of six cases the Signaled-RIFI gradients were between the FI and RIFI gradients. In other words, regardless of whether the FI or RIFI response-rate gradient was higher at any point in the interval, response rates in the corresponding Signaled-RIFI schedule were intermediate of the two in four of six cases. This was especially obvious during the first half of the schedules. Visual inspection of raster plots (Appendix B Figure B3 and Figure B4) confirmed these differences in responding in FI, RIFI, and Signaled-RIFI schedules.

Aggregated response-rate gradients shown in Figure 15 show responding increasing gradually as time to food decreased in the three schedule types. However, visual inspection of responding in individual trials indicated that responding in all schedule types could be characterized as low-high in nature: a relatively low rate of responding early in the interval, followed by a change at a breakpoint to a relatively high rate of responding until food was delivered. Breakpoints were calculated using Equation 1 in the same manner as in Experiment 1 and are shown in Figure 16. The same trial exclusionary criteria were used as well and a RM ANOVA on the number of trials excluded from the analysis with schedule type and interval duration as factors revealed no significant differences (all $p s>.05$ ). A significantly greater number of trials were not excluded from any one schedule type. A RM ANOVA on breakpoint with schedule type and interval duration as factors revealed a significant effect of interval ( $p<$ 
.01), but not of schedule type or the schedule type $\mathrm{x}$ interval duration interaction. Breakpoints were longer in the 30-s schedules, but not different between schedule types.

While mean breakpoints for all three pigeons were not systematically or significantly different between the three schedule types, mean breakpoints in the Signaled-RIFI schedule were, at the very least, between the mean FI and RIFI breakpoints, and were often more similar to the mean FI breakpoint than the mean RIFI breakpoint. Aggregated across pigeons, the mean difference in mean breakpoint between the FI and RIFI schedules was 1.85 s (SEM=1.12); compared to $1.68 \mathrm{~s}(S E M=0.87)$ between the RIFI and Signaled-RIFI schedules; and, finally, the closest mean breakpoints were between the FI and Signaled-RIFI schedules at $1.46 \mathrm{~s}$ (SEM= 1.24) apart. In five out of six individual comparisons (three pigeons $x$ two interval durations) the mean breakpoint in the Signaled-RIFI schedule was closer to the mean breakpoint in the FI schedule than the RIFI schedule.

As in Experiment 1, the functional relationship between response rate and time since trial onset (Figure 15) may reveal differences between the three schedule types not detected by comparing single-trial measures such as first-response latency and breakpoint. However, to compare how response rates changed as time to food decreased (i.e., response patterns) overall differences in absolute response rates obtained in the schedule types had to be controlled for. To do so, the gradients from Figure 15 were normalized in the same manner as in Experiments 1 and 2. This adjustment ensured that the normalized response rate curves for all the gradients in both schedules ranged from 0 (the normalized minimum response rate) to 1 (the normalized maximum response rate). By normalizing the response-rate gradients the general pattern of changes in response rate across the intervals in the three schedule types could be compared while controlling for the differences in absolute rate that were observed. Figure 17 shows normalized response rate 
as a function of normalized time (in bins equal to $10 \%$ of the corresponding interval) for each pigeon in each condition.

For a quantitative characterization of the functional relation between response rate and time since the onset of the fixed interval, an ogive function (Guilhardi \& Church, 2005) was fitted to the normalized response-rate gradients using Equation 2.

For 16 out of 18 of the ogive fits, VAC was .96 or greater. The two exceptions were .92 VAC for Pigeon 401 in the Signaled-RIFI 15-s condition, and .94 VAC for Pigeon 402 in the RIFI 15-s condition. Parameter estimates from Equation 2 are listed in Table 5. Separate RM ANOVA on the $a$ and $b$ parameter estimates revealed no significant differences; however, consistent with the breakpoint analysis, the midpoint (a) parameter in Signaled-RIFI schedules was between the midpoint parameter in the FI and RIFI schedules in five of six comparisons, and was often closer to the obtained midpoint parameter in the corresponding FI schedule. There were no systematic differences in the slope $(b)$ parameter across pigeons and schedule types.

\section{Discussion}

In Experiment 3, three pigeons were exposed to FI, RIFI, and Signaled-RIFI 15- and 30-s schedules of reinforcement. Unlike in Experiments 1 and 2, there was no yoking arrangement and reinforcement rates were free to vary between the schedule types. In addition, all trials in Experiment 3 ended in food delivery. The results suggest that the signaling of the initiatingresponse in the Signaled-RIFI schedules produced patterns of behavior that were more similar to those observed in FI. This signaling also appeared to enhance the saliency of the intervalinitiating response, which resulted in decreased first-response latencies and higher reinforcement rates in the Signaled-RIFI schedules than the RIFI schedules. 
Individual-subject VAC confirm Equation 2 provided an accurate quantitative characterization of normalized response-rate gradients for all three schedule types in Experiment 3. Ogive fits and visual inspection of normalized response-rate gradients indicated that in four of six cases response patterning in the Signaled-RIFI schedule was intermediate of response patterning in the FI and RIFI schedules, regardless of whether responding in the RIFI schedule was occurring at a relatively higher or lower rate than responding in the FI schedule. In the other two cases, the normalized response-rate gradients for all three schedules were either similar (401, 30-s condition) or the Signaled-RIFI gradient more closely approximated the RIFI gradient (403, 15-s condition). In all cases mean breakpoints in the Signaled-RIFI schedules were intermediate of those obtained in the FI and RIFI schedules. The breakpoint analysis also indicated that breakpoints in the Signaled-RIFI schedules were more similar to those obtained in the FI than RIFI schedules in five of six cases.

Based on normalized response-rate gradients, ogive fits, and breakpoints, temporal discrimination did not differ systematically between the schedule types. While signaling the initiating response had a consistent and systematic effect on first-response latencies and reinforcement rates, the differences obtained between the three schedule types did not indicate better temporal discrimination in any one schedule type. Although the results of Experiment 2 suggest that timing precision is reduced in RIFI schedules relative to FI schedules and the results of Experiment 3 suggest that response patterning in Signaled-RIFI schedules is more similar to that observed in FI than RIFI schedules, additional evidence is necessary conclude that timing precision in Signaled-RIFI schedules is more precise than that observed in RIFI schedules and indeed more like that observed in FI schedules. Specifically, that additional evidence would 
include a comparison of performance in the three schedule types during no-food trials when overall reinforcement rates are controlled for-similar to the arrangement in Experiment 2.

The absolute response-rate gradients and first-response latencies obtained in the FI, RIFI, and Signaled-RIFI schedules in Experiment 3 were consistent with previous research (Fox \& Kyonka, 2013; Rutter, 1990; Shull, 1970b) and Experiments 1 and 2. Absolute response rates were higher early in the RIFI schedules compared to the FI schedules and first-response latencies tended to be longer in the RIFI schedules, although not quite to the extent that was observed by Fox and Kyonka or in Experiments 1 and 2.

Effects of signaling the initiating response may be considered similar to effects of signaling in other experimental preparations. Signaling a delay to reinforcement can produce conditioned-reinforcement effects on behavior that unsignaled delays do not (e.g., Richards, 1981). In delay-discounting procedures, signaling a delay to the larger-later reinforcer (the "selfcontrolled" choice) can increase self-control—an effect that is enhanced when $d$-amphetamine is administered (e.g., Cardinal, Robbins, \& Everitt, 2000)—an apparent conditioned-reinforcing effect as well. Therefore, it is plausible that the decreased first-response latencies observed in the Signaled-RIFI schedules were due to a conditioned-reinforcement effect: The first response produced a stimulus that was correlated with food and extinguished a stimulus that was not. The increased rates of reinforcement in the Signaled-RIFI schedule may have been an artifact of this conditioned-reinforcement effect. Changes in temporal discrimination, though, would occur separately from changes in the time of the initiating response that resulted from the conditionedreinforcing effects of the stimulus change (i.e., the signal). Additional research is needed to assess if the decreased first-response latencies and changes in response-rate gradients observed in Experiment 3 caused by signaling the initiating response were due to a conditioned- 
reinforcement effect alone or if signaling the initiating response also resulted in changes to temporal discrimination.

\section{General Discussion}

In Experiments 1 and 2, pigeons were exposed to FI and RIFI schedules of reinforcement. In these experiments, the key peck (RIFI) and key-light illumination (FI) time markers were isolated by controlling for differences in reinforcement rate between the two schedule types. In both experimental preparations food delivery was not a better predictor of when future food would be available in either schedule. Experiment 2 employed a peak procedure in an attempt to more precisely assess how the two types of time markers might affect temporal discrimination and to uncover potential differences between how each functions. The results of Experiment 1 suggest that higher response rates early in the RIFI schedules relative to the FI schedules are caused by the response-initiation requirement and not lower reinforcement rates and longer more variable IFIs in the RIFI schedules previously observed by Fox and Kyonka (2013). Results from the no-food trials in Experiment 2 further supported the results from Experiment 1 and suggest that while timing accuracy was unaffected by the type of time marker employed, timing precision was reduced in the RIFI schedule.

The objective of Experiment 3 was to assess behavior during timed intervals initiated via a combination of a response and stimulus change. To do so pigeons were exposed to FI, RIFI, and Signaled-RIFI schedules of reinforcement. In Experiment 3 reinforcement rates were free to vary depending on the first-response latencies in the schedules - these responses initiated the interval in the RIFI and Signaled-RIFI schedules. The signaling of the initiating response via both a stimulus color and location change in the Signaled-RIFI schedules resulted in shorter firstresponse latencies and higher reinforcement rates than in the un-signaled RIFI schedules. 
The results of Experiment 2 suggest that reductions in timing precision when an organism must rely solely on its own past behavior may be both subtle and vary in degree from organism to organism, but are not inconsequential. Furthermore, the results from Experiment 3 suggest that signaling a response time marker with an exteroceptive stimulus change may enhance the saliency of that time marker. This is especially important when considering how to improve the timing precision of newly trained behaviors in populations with psycho-neurological impairments associated with temporal discrimination deficits.

Consider the degree of timing precision required in a conversation between two people. Even small disruptions in the precision with which behaviors occur in time can be the difference between a person being reinforced or punished in that social context. The importance of the precision of timing behavior in social situations is even more apparent when considered in the context of early childhood development and in the treatment of developmental disabilities. If a child with autism is being trained to time some future behavior using only his or her own past behavior, the precision with which the future behavior occurs may be reduced not only because of the impairments associated with autism (e.g., Allman et al., 2011), but because of the response time marker employed. The results of Experiment 3 suggest that signaling that response time marker during training may enhance its saliency, thus potentially reducing the training time necessary to acquire the new behavior. Perhaps the signal could then be faded over time.

Research has shown that some variables related to motivation (e.g., reinforcer magnitude) may affect response patterning, the duration of the first-response latency, and response rate during interval schedules (e.g., Galtress \& Kirkpatrick, 2009; Lowe, Davey, \& Harzem, 1974; Ludvig, Balci, \& Spetch, 2011). These studies and the results of Experiments 1-3 raise interesting questions about the relation between motivation and timing-specifically, how to 
tease the two apart. The time markers employed in Experiments 1-3 were unrelated to motivation, and by using the yoking procedure, overall reinforcement rates and assumedly any potential differences in motivation in the two schedule types in Experiments 1 and 2 were controlled for. Yet the nature of the time marker affected timing precision in Experiment 2. It also affected the rate at which responding occurred during the interval to food and the firstresponse latency on individual trials in Experiments 1-3. How variables related to motivation and time marker dimension affect temporal discrimination singularly or in combination is not yet well understood, however, based on the results of Experiments 2 in particular, exteroceptive stimulus changes appear to be more efficacious time markers that result in more precise timing than responses_-apart from any differences in variables related to motivation.

Due to the array of variables discussed that affect dependent measures associated with temporal discrimination in interval schedules and peak procedure variations of interval schedules, a new approach that better isolates independent variables may be beneficial. Interval schedules and the peak procedure rely on response rate and response latency as primary dependent variables of temporal discrimination. It has been shown that variables related to motivation and "state” affect response rate apart from having any effect on temporal discrimination (e.g., Ludvig, Balci, \& Spetch, 2011; Odum, 2002; Odum, Lieving, \& Schaal, 2002; Plowright, Church, Behnke, \& Silverman, 2000). The omission of reinforcers, which is a central component of the peak procedure, has also been shown to systematically affect responding in FI schedules (e.g., Staddon \& Innis, 1969). It is therefore difficult to determine the extent to which these manipulations are affecting temporal discrimination apart from other changes they produce in behavior. What is needed is a procedure that isolates changes in temporal discrimination from changes in other variables, and in particular, from changes in 
motivation and attention. Variations of the free-operant psychophysical choice procedure (FOPC) may be ideal for this reason (Bizo \& White, 1994, 1995; Stubbs, 1980). The main dependent variable in the FOPC procedure is the time in which the animal switches from one manipulandum to another (often referred to as the point of subjective equality (PSE) because when responding is aggregated across trials it is the point in time in which responding was equally likely to be occurring on either manipulandum). Although response rates are an important determinant of the PSE, changes in response rate caused by motivation or "state" related variables should not affect it, even though they may "flatten” or "sharpen” the psychophysical functions. In addition, FOPC procedures that employ two FI schedules may be particular useful because every trial ends in reinforcement (Platt \& Davis, 1983). In variations of the FOPC which employ two variable-interval (VI) schedules, reinforcement is typically withheld during trials that are used for analysis (e.g., Cheung et al., 2007). These "empty" or "probe” trials may affect behavior and timing, just as behavior in FI schedules is affected when reinforcers are omitted (Staddon \& Innis, 1969). It may be a useful extension of Experiments 1-3 to compare responses and stimuli as time markers in a FOPC procedure. If response time markers result in equivalent timing accuracy but reduced timing precision as suggested by the results of Experiment 2, the PSE would be unaffected, but the variability associated with it would be greater.

The results of Experiments 1-3 and previous research outlined above are problematic for the predominant models of interval timing: Scalar Expectancy Theory (Gibbon, 1977) and the Behavioral Theory of Timing (Killeen \& Fetterman, 1988; see also Machado, 1997). That variables related to motivation, time marker dimension, and general experimental procedure affect dependent measures of temporal discrimination, suggests that the models, which do not 
account for such factors, must be modified. Even more contemporary models that attempt to explain temporal processing in neurological terms such as the Striatal Beat Frequency model (Matell \& Meck, 2000, 2004) do not adequately describe how changes in the variables described above might cause changes in temporal discrimination, and, furthermore, how various brain regions are implicated in temporal processing when different time marker and motivational variables are at work. For example, recent research suggests that the timing of reinforcement delivery is at least partially timed by changes in the visual cortex when the time marker signaling the onset of the interval to reinforcement is a change in a visual stimulus (Shuler \& Bear, 2006). A model of temporal processing that includes all such factors does not yet exist, and, indeed the full complexity of temporal processing is not yet understood.

Time is a powerful determinant of behavior. Adaptive behavior relies on organizing events temporally, anticipating when future events will occur, and engaging in behaviors at appropriate times. While research is beginning to show that variables related to motivation and time marker dimension may affect temporal discrimination, the most influential models of interval timing do not yet include parameters to account for such differences. The present set of experiments coupled with recent research suggests temporal discrimination may be affected by a much more complex array of variables than previously thought. These variables seemingly all interact simultaneously to affect temporal processing and behavior. The results of Experiment 1 suggest that differences in behavior controlled by FI and RIFI schedules are a product of the response-initiation requirement in RIFI schedules and not differences in the overall rate of food delivery. Experiment 2 showed that future behavior may be timed with less precision when an organism must rely solely on its own past behavior. Finally, in Experiment 3 signaling the first response in RIFI schedules decreased first-response latencies and resulted in response patterning 
more like that observed in FI schedules, suggesting that such signaling may improve timing precision. Experiments 1-3 demonstrated some preliminary steps that can be taken to isolate time marker dimension as an independent variable with fruitful results. It will be important for future research assessing the independent effects of time marker dimension, motivation, or attention on temporal discrimination to isolate the effects of the independent variable of interest apart from other potential changes in behavior that are unrelated to changes in temporal discrimination. 


\section{References}

Allman, M. J., DeLeon, I. G., \& Wearden, J. H. (2011). Psychophysical assessment of timing in individuals with autism. American Journal on Intellectual and Developmental Disabilities, 116, 165-178.

Balci, F., Ludvig, E.A., Abner, R., Zhuang, X., Poon, P., \& Brunner, B.D. (2010). Motivational effects on interval timing in dopamine transporter (DAT) knockdown mice. Brain Research, 1325, 89-99.

Balci, F., Ludvig, E.A., \& Brunner, D. (2010). Within-session modulation of timed anticipatory responding: when to start responding. Behavioural Processes, 85, 204-206.

Bizo, L. A., \& White, K. G. (1994). Pacemaker rate in the behavioral theory of timing. Journal of Experimental Psychology: Animal Behavior Processes, 20, 308-321.

Bizo, L. A., \& White, K. G. (1995). Reinforcement context and pacemaker rate in the behavioral theory of timing. Animal Learning \& Behavior, 23, 376-382.

Body, S., Cheung, T. H. C., Valencia-Torres, L., Olarte-Sanchez, C. M., Fone, K. D. F., Bradshaw, C. M., \& Szabadi, E. (2013). Pharmacological studies on performance on the free-operant psychophysical procedure. Behavioural Processes.

Branch, M. N., \& Gollub, L. R. (1974). A detailed analysis of the effects of d-amphetamine on behavior under fixed-interval schedules. Journal of the Experimental Analysis of Behavior, 21, 519-539.

Buhusi, C. V., \& Meck, W. H. (2000). Timing for the absence of a stimulus: The gap paradigm reversed. Journal of Experimental Psychology: Animal Behavior Processes, 26, 305-322. 
Buhusi, C. V., \& Meck, W. H. (2006a). Interval timing with gaps and distracters: evaluation of the ambiguity, switch, and time-sharing hypotheses. Journal of Experimental Psychology: Animal Behavior Processes, 32, 329-338.

Buhusi, C. V., \& Meck, W. H. (2006b). Time sharing in rats: A peak-interval procedure with gaps and distractors. Behavioral Processes, 71, 107-115.

Caetano, M. S., \& Church, R.M. (2009). A comparison of responses and stimuli as time markers. Behavioural Processes, 81, 298-302.

Capehart, G. W., Eckerman, D. A., Guilkey, M., \& Shull, R. L. (1980). A comparison of ratio and interval reinforcement schedules with comparable interreinforcement times. Journal of the Experimental Analysis of Behavior, 34, 61-76.

Cardinal, R. N., Robbins, R. W., \& Everitt, B. J. (2000). The effects of $d$-amphetamine, chlordiazepoxide, $\alpha$-flupenthixol and behavioural manipulations on choice of signaled and unsignalled delayed reinforcement in rats. Psychopharmacology, 152, 362-375.

Catania, A. C. (1970). Reinforcement schedules and pscyho-physical judgments: A study of some temporal properties of behavior. In W. N. Schoenfeld (Ed.), The theory of reinforcement schedules. New York: Appleton-Century-Croft.

Catania, A. C., \& Reynolds, G. S. (1968). A quantitative analysis of the responding maintained by interval schedules of reinforcement. Journal of the Experimental Analysis of Behavior, $28,155-161$.

Cheung, T. H. C., Bezzina, G., Hampson, C. L., Body, S., Fone, K. C. F., Bradshaw, C. M., \& Szabadi, E. (2007). Evidence for the sensitivity of operant timing behaviour to stimulation of D1 dopamine receptors. Psychopharmacology, 195, 213-222. 
Chung, S. H., \& Neuringer, A. J. (1967). Control of responding by a percentage reinforcement schedule. Psychonomic Science, 8, 25-26.

Church, R. M., Meck, W. H., \& Gibbon, J. (1994). Application of scalar timing theory to individual trials. Journal of Experimental Psychology: Animal Behavior Processes, 20, 135-155.

Dews, P. B. (1978). Studies on responding under fixed-interval schedules of reinforcement: II. The scalloped pattern of the cumulative record. Journal of the Experimental Analysis of Behavior, 29, 67-75.

Droit-Volet, S., \& Meck, W. H. (2007). How emotions colour our perception of time. Trends in Cognitive Sciences, 11, 504-513.

Fox, A. E., \& Kyonka, E. G. E. (2013). Pigeon responding on fixed-interval and responseinitiated fixed-interval schedules. Journal of the Experimental Analysis of Behavior. Accepted for publication.

Freestone, D. M., \& Church, R. M. (2010). The importance of the reinforcer as a time marker. Behavioural Processes, 84, 500-505.

Galtress, T., \& Kirkpatrick, K. (2009). Reward value effects on timing in the peak procedure. Learning and Motivation, 40, 109-131.

Gentry, G. D., Weiss, B., \& Laties, V. G. (1983) The microanalysis of fixed-interval responding. Journal of the Experimental Analysis of Behavior, 39, 327-343.

Gibbon, J. (1977). Scalar expectancy theory and Weber's law in animal timing. Psychological review, 84, 279-325.

Goldston, S., \& Lhamon, W. T. (1974). Studies of auditory-visual differences in human time judgment: Sounds are judged longer than lights. Perceptual and Motor Skills, 39, 63-82. 
Guilhardi, P., \& Church, R. M. (2004). Measures of temporal discrimination in fixed-interval performance: A case study in archiving data. Behavior Research Methods, Instruments, \& Computers, 36(4), 661-669.

Guilhardi, P., \& Church, R. M. (2005). Dynamics of temporal discrimination. Learning and Behavior, 33, 399-416.

Higa, J. J., Wynne, C. D. L., \& Staddon, J. E. R. (1991). Dynamics of time discrimination. Journal of Experimental Psychology: Animal Behavior Processes, 17, 281-291.

Killeen, P. R., \& Fetterman, J. G. (1988). A behavioral theory of timing. Psychological Review, 95, 274-295.

Kirkpatrick, K., Miller, S. S., Betti, C. A., \& Wasserman, E. A. (1996). Cyclic responding by pigeons on the peak timing procedure. Journal of Experimental Psychology: Animal Behavior Processes, 22, 447-460.

Kraemer, P. J., Brown, R. W., \& Randall, C. K. (1995). Signal intensity and duration estimation in rats. Behavoural Processes, 34, 265-268.

Kyonka, E. G. E., \& Grace, R. C. (2010). Rapid acquisition of choice and timing and the provenance of the terminal-link effect. Journal of the Experimental Analysis of Behavior, 94, 209-225.

Langer, J., Wapner, S., \& Werner, H. (1961). The effect of danger upon the experience of time. American Journal of Psychology, 74, 94-97.

Lau, B., \& Glimcher, P. W. (2005). Dynamic response-by-response models of matching behavior in rhesus monkeys. Journal of the Experimental Analysis of Behavior, 84, 555-579.

Lejeune, H., \& Wearden, J. H. (1991). The comparative psychology of fixed-interval responding: Some quantitative analyses. Learning and Motivation, 22, 84-111. 
Lowe, C. F., Davey, G. C. L., \& Harzem, P. (1974). Effects of reinforcement magnitudes on interval and ratio schedules. Journal of the Experimental Analysis of Behavior, 22, 553560.

Ludvig, E. A., Balci, F., \& Spetch, M. L. (2011). Reward magnitude and timing in pigeons. Behavioural Processes, 86, 359-363.

Machado, A. (1997). Learning the temporal dynamics of behavior. Psychological Review, 104, 241-265.

Matell, M. S., Bateson, M., \& Meck, W. H. (2006). Single-trials analyses demonstrate that increases in clock speed contribute to the methamphetamine-induced horizontal shifts in peak-interval timing functions. Psychopharamacology, 188, 201-212.

Matell, M. S., King, G. R., \& Meck, W. H. (2004). Differential modulation of clock speed by the administration of intermittent versus continuous cocaine. Behavioral Neuroscience, 118, 150-156.

Matell, M. S., \& Meck, W. H. (2000). Neuropsychological mechanisms of interval timing behavior. BioEssays, 22, 94-103.

Matell, M. S., \& Meck, W. H. (2004). Cortico-striatal circuits and interval timing: Coincidence detection of oscillatory processes. Cognitive Brain Research, 21, 139-170.

Mechner, F., Guevrekian, L., \& Mechner, V. (1963). A fixed interval schedule in which the interval is initiated by a response. Journal of the Experimental Analysis of Behavior, 6, 323-330.

Nevin, J. A. (1971). Rates and patters of responding with concurrent fixed-interval and variableinterval reinforcement. Journal of the Experimental Analysis of Behavior, 16, 241-247.

Odum, A. L. (2002). Behavioral pharmacology and timing. Behavioural Processes, 57, 197-120. 
Odum, A. L., Lieving, L. M., \& Schaal, D. W. (2002). Effects of $d$-amphetamine in a temporal discrimination procedure: Selective changes in timing or rate dependency? Journal of the Experimental Analysis of Behavior, 78, 195-214.

Penny, T. B., Gibbon, J., \& Meck, W. H. (2000). Differential effects of auditory and visual signals on clock speed and temporal memory. Journal of Experimental Psychology: Human Perception and Performance, 26, 1770-1787.

Perone, M. (1991). Experimental design in the analysis of free-operant behavior. In K. A. Lattal \& I. Iversen (Eds.), Experimental Analysis of Behavior, Part I (pp. 135-171). Amsterdam: Elsevier.

Platt, J. R., \& Davis, E. R. (1983). Bisection of temporal intervals by pigeons. Journal of Experimental Psychology: Animal Behavior Processes, 9, 160-170

Plowright, C.M.S., Church, D., Behnke, P., \& Silverman, A. (2000). Time estimation by pigeons on a fixed interval: the effect of pre-feeding. Behavioural Processes, 52, 43-48.

Rammsayer, T., \& Classen, W. (1997). Impaired temporal discrimination in Parkinson’s disease: Temporal processing of brief durations as an indicator of degeneration of dopaminergic neurons in the basal ganglia. International Journal of Neuroscience, 91, 45-55.

Richards, R. W. (1981). A comparison of signaled and unsignaled delay of reinforcement . Journal of the Experimental Analysis of Behavior, 35, 145-152.

Roberts, S. (1981). Isolation of an internal clock. Journal of Experimental Psychology: Animal Behavior Processes, 7, 242-268.

Roberts, S., \& Church, R. M. (1978). Control of an internal clock. Journal of Experimental Psychology: Animal Behavior Processes, 4, 318-337. 
Rutter, S. (1990). Responding initiated by pecks on a start key. Behavioural Processes, 21, 5967.

Santi, A., Miki, A., \& Hornyak, S. (2006). The perception of empty and filled time intervals by rats. Behavioural Processes, 71, 144-156.

Schneider, B. A. (1969). A two-state analysis of fixed-interval responding in the pigeon. Journal of the Experimental Analysis of Behavior, 12, 677-687.

Shuler, M. G., \& Bear, M. F. (2006). Reward timing in the primary visual cortex. Science, 311, 1606-1609.

Shull, R. (1970a). A response-initiated fixed-interval schedule of reinforcement. Journal of the Experimental Analysis of Behavior, 13, 13-15.

Shull, R. (1970b). The response-reinforcement dependency in fixed-interval schedules of reinforcement. Journal of the Experimental Analysis of Behavior, 14, 55-60.

Skinner, B. F. (1938). The behavior of organisms. New York: Appleton-Century-Crofts.

Staddon, J. E. R., \& Innis, N. K. (1969). Reinforcement omission on fixed-interval schedules. Journal of the Experimental Analysis of Behavior, 12, 689-700.

Stubbs, D. A. (1980). Temporal discrimination and a free-operant psychophysical procedure. Journal of the Experimental Analysis of Behavior, 33, 167-185.

Vasconcelos, M., \& Urcuioli, P. J. (2008). Deprivation level and choice in pigeons: A test of within-trial contrast. Learning \& Behavior, 36, 12-18.

Ward, R. D., \& Odum, A. L. (2006). Effects of prefeeding, intercomponent-interval food, and extinction on temporal discrimination and pacemaker rate. Behavioural Processes, 71, 297-306. 
Ward, R. D., \& Odum, A. L. (2007). Disruption of temporal discrimination and the choose-short effect. Learning \& Behavior, 35, 60-70.

Ward, R. D., Kellendonk, C., Simpson, E. H., Lipatova, O., Drew, M. R., Fairhurst, S., Kandel, E. R., \& Balsam, P. D. (2009). Impaired timing precision produced by striatal D2 receptor overexpression is mediated by cognitive and motivational deficits. Behavioral Neuroscience, 123, 720-730.

Ward, R. D., Kellendonk, C., Kandel, E. R., \& Balsam, P. D. (2012). Timing as a window on cognition in schizophrenia. Neuropharmacology, 62, 1175-1181.

Watts, F. N., \& Sharrock, R. (1984). Fear and time estimation. Perceptual and Motor Skills, 59, 597-598.

Weaver, M. T., \& Branch, M. N. (2008). Tolerance to effects of cocaine on behavior under a response-initiated fixed-interval schedule. Journal of the Experimental Analysis of Behavior, 90, 207-218.

Wynne, C. D. L., \& Staddon, J. E. R. (1988). Typical delay determines waiting time on periodicfood schedules: Static and dynamic tests. Journal of the Experimental Analysis of Behavior, 50, 197-210. 
Table 1

Median first-response latencies for Pigeons 301-303 in Experiment 1 with corresponding interquartile ranges (IQR) and ranges

\begin{tabular}{cccccccccc} 
& & \multicolumn{3}{c}{ FI } & & \multicolumn{3}{c}{ RIFI } \\
\cline { 3 - 6 } \cline { 7 - 9 } Pigeon & Interval (s) & Median & IQR & Range & & Median & IQR & Range \\
\hline 301 & 15 & 3.20 & 5.00 & 11.63 & & 4.25 & 4.13 & 16.34 \\
& 30 & 3.93 & 6.47 & 16.57 & & 5.61 & 4.10 & 13.71 \\
302 & 15 & 4.67 & 2.33 & 9.88 & & 8.62 & 5.61 & 17.49 \\
& 30 & 7.09 & 4.92 & 17.91 & & 11.70 & 8.75 & 35.50 \\
& 15 & & & & & & & & \\
303 & 15 & 6.77 & 4.45 & 70.43 & & 10.41 & 9.20 & 33.13 \\
& 30 & 12.12 & 27.02 & 106.32 & & 13.72 & 14.65 & 786.97 \\
\hline
\end{tabular}

Note. FI = Fixed Interval; RIFI = Response-Initiated Fixed Interval; IQR = Interquartile Range. 
Table 2

Ogive parameter estimates (Equation 2) for Pigeons 301-303 in Experiment 1

\begin{tabular}{cccccc} 
& & \multicolumn{5}{c}{ Schedule (type/length (s)) } \\
\cline { 3 - 6 } Pigeon & Parameter & FI 15 & RIFI 15 & FI 30 & RIFI 30 \\
\hline 301 & $a$ & 0.49 & 0.57 & 0.37 & 0.47 \\
& $b$ & 0.12 & 0.15 & 0.11 & 0.15 \\
302 & $a$ & 0.41 & 0.29 & 0.44 & 0.28 \\
& $b$ & 0.09 & 0.10 & 0.09 & 0.06 \\
303 & $a$ & 0.61 & 0.52 & 0.60 & 0.61 \\
& $b$ & 0.14 & 0.15 & 0.16 & 0.13 \\
\hline
\end{tabular}

Note. FI = Fixed Interval; RIFI = Response-Initiated Fixed Interval. 
Table 3

Median first-response latencies for Pigeons 301-303 in Experiment 2 with corresponding interquartile ranges (IQR) and ranges

\begin{tabular}{|c|c|c|c|c|c|c|c|}
\hline \multirow[b]{2}{*}{ Pigeon } & \multirow{2}{*}{$\begin{array}{c}\text { Interval } \\
\text { (s) }\end{array}$} & \multicolumn{3}{|c|}{ FI } & \multicolumn{3}{|c|}{ RIFI } \\
\hline & & Median & IQR & Range & Median & IQR & Range \\
\hline \multirow[t]{2}{*}{301} & 15 & 3.33 & 2.33 & 6.93 & 5.23 & 4.62 & 15.07 \\
\hline & 30 & 5.55 & 3.21 & 13.75 & 5.07 & 5.41 & 21.75 \\
\hline \multirow[t]{2}{*}{302} & 15 & 4.57 & 2.13 & 7.43 & 11.64 & 8.37 & 21.76 \\
\hline & 30 & 8.34 & 5.37 & 17.27 & 18.54 & 10.29 & 51.78 \\
\hline \multirow[t]{2}{*}{303} & 15 & 4.67 & 2.21 & 8.11 & 5.69 & 6.65 & 20.94 \\
\hline & 30 & 9.08 & 5.74 & 19.56 & 16.77 & 14.52 & 54.27 \\
\hline
\end{tabular}

Note. FI = Fixed Interval; RIFI = Response-Initiated Fixed Interval; IQR = Interquartile Range. 
Table 4

Median first-response latencies for Pigeons 401-403 in Experiment 3 with corresponding inter-quartile ranges (IQR) and ranges

\begin{tabular}{|c|c|c|c|c|c|c|c|c|c|c|}
\hline \multirow[b]{3}{*}{ Pigeon } & \multirow{3}{*}{$\begin{array}{c}\text { Interval } \\
\text { (s) }\end{array}$} & \multicolumn{9}{|c|}{ Schedule } \\
\hline & & \multicolumn{3}{|c|}{ FI } & \multicolumn{3}{|c|}{ RIFI } & \multicolumn{3}{|c|}{ Signaled-RIFI } \\
\hline & & Median & IQR & Range & Median & IQR & Range & Median & IQR & Range \\
\hline \multirow[t]{2}{*}{401} & 15 & 4.13 & 4.54 & 13.68 & 2.44 & 3.55 & 18.43 & 2.52 & 3.08 & 13.82 \\
\hline & 30 & 6.14 & 8.99 & 25.50 & 5.81 & 8.08 & 21.22 & 2.23 & 4.58 & 47.21 \\
\hline \multirow[t]{2}{*}{402} & 15 & 6.32 & 4.52 & 13.44 & 4.07 & 5.08 & 20.61 & 2.84 & 1.58 & 17.24 \\
\hline & 30 & 13.57 & 6.63 & 24.97 & 15.92 & 11.20 & 38.28 & 8.11 & 11.63 & 296.16 \\
\hline \multirow[t]{2}{*}{403} & 15 & 8.82 & 3.80 & 14.49 & 5.32 & 5.82 & 20.04 & 4.16 & 2.87 & 14.90 \\
\hline & 30 & 12.67 & 10.23 & 25.88 & 21.68 & 12.89 & 84.20 & 7.47 & 8.17 & 73.91 \\
\hline
\end{tabular}

Note. $\mathrm{FI}=$ Fixed Interval; RIFI = Response-Initiated Fixed Interval; IQR = Interquartile Range. 
Table 5

Ogive parameter estimates (Equation 2) for Pigeons 401-403 in Experiment 3

\begin{tabular}{cccccccc} 
& & \multicolumn{7}{c}{ Schedule (type/length (s)) } \\
\cline { 3 - 7 } Pigeon & Parameter & 15 & RIFI 15 & SRIFI 15 & 30 & RIFI 30 & SRIFI 30 \\
\hline \multirow{2}{*}{401} & $a$ & 0.34 & 0.53 & 0.38 & 0.39 & 0.36 & 0.41 \\
& $b$ & 0.12 & 0.17 & 0.19 & 0.10 & 0.09 & 0.16 \\
& & & & & & & \\
402 & $a$ & 0.47 & 0.26 & 0.41 & 0.53 & 0.29 & 0.43 \\
& $b$ & 0.09 & 0.08 & 0.07 & 0.08 & 0.09 & 0.08 \\
& & & & & & & \\
& $a$ & 0.63 & 0.37 & 0.38 & 0.59 & 0.38 & 0.49 \\
& $b$ & 0.10 & 0.07 & 0.09 & 0.10 & 0.11 & 0.10 \\
\hline
\end{tabular}

Note. FI = Fixed Interval; RIFI = Response-Initiated Fixed Interval. 


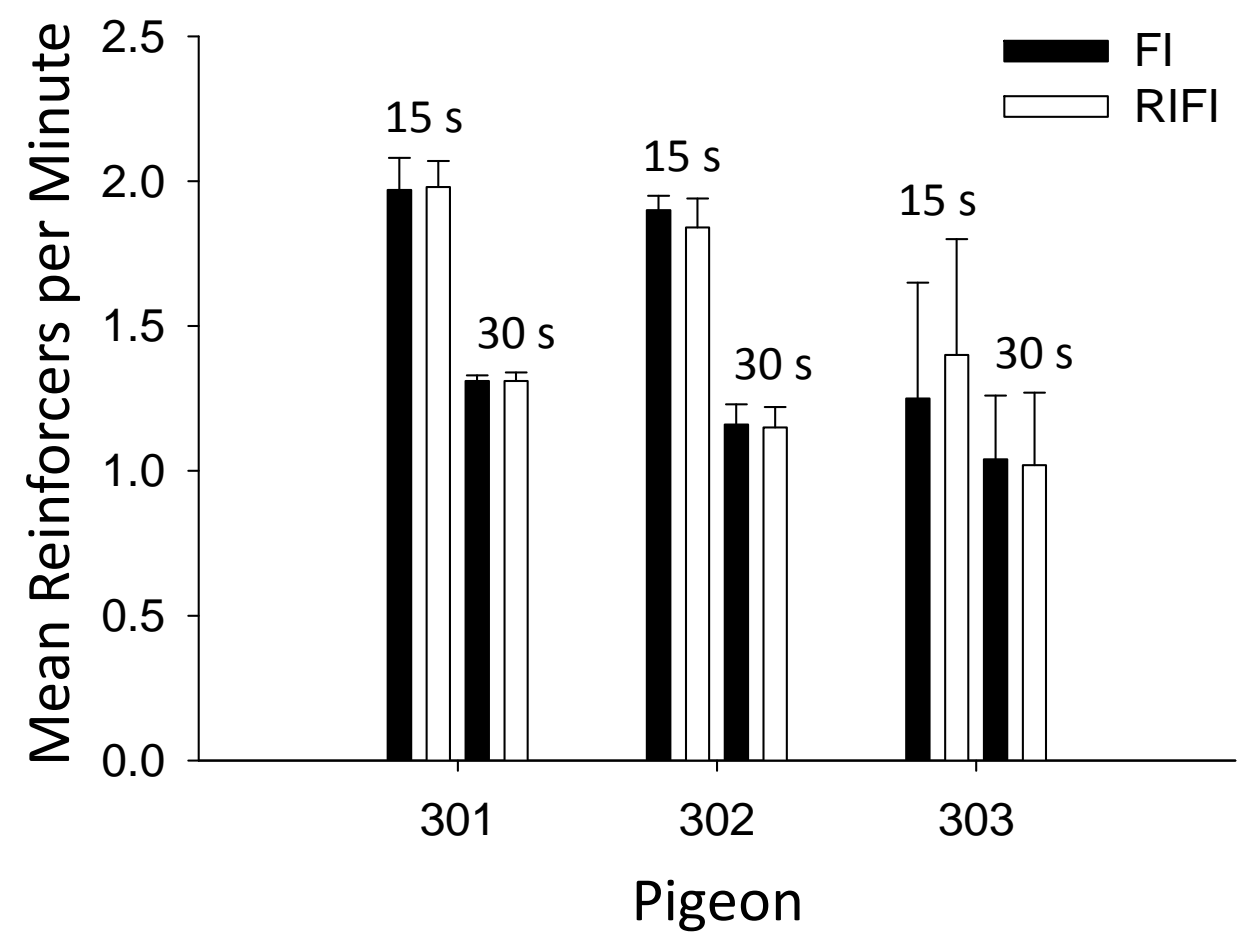

Figure 1. Mean reinforcers per minute for each pigeon in each condition of Experiment 1. Error bars represent standard deviations. 


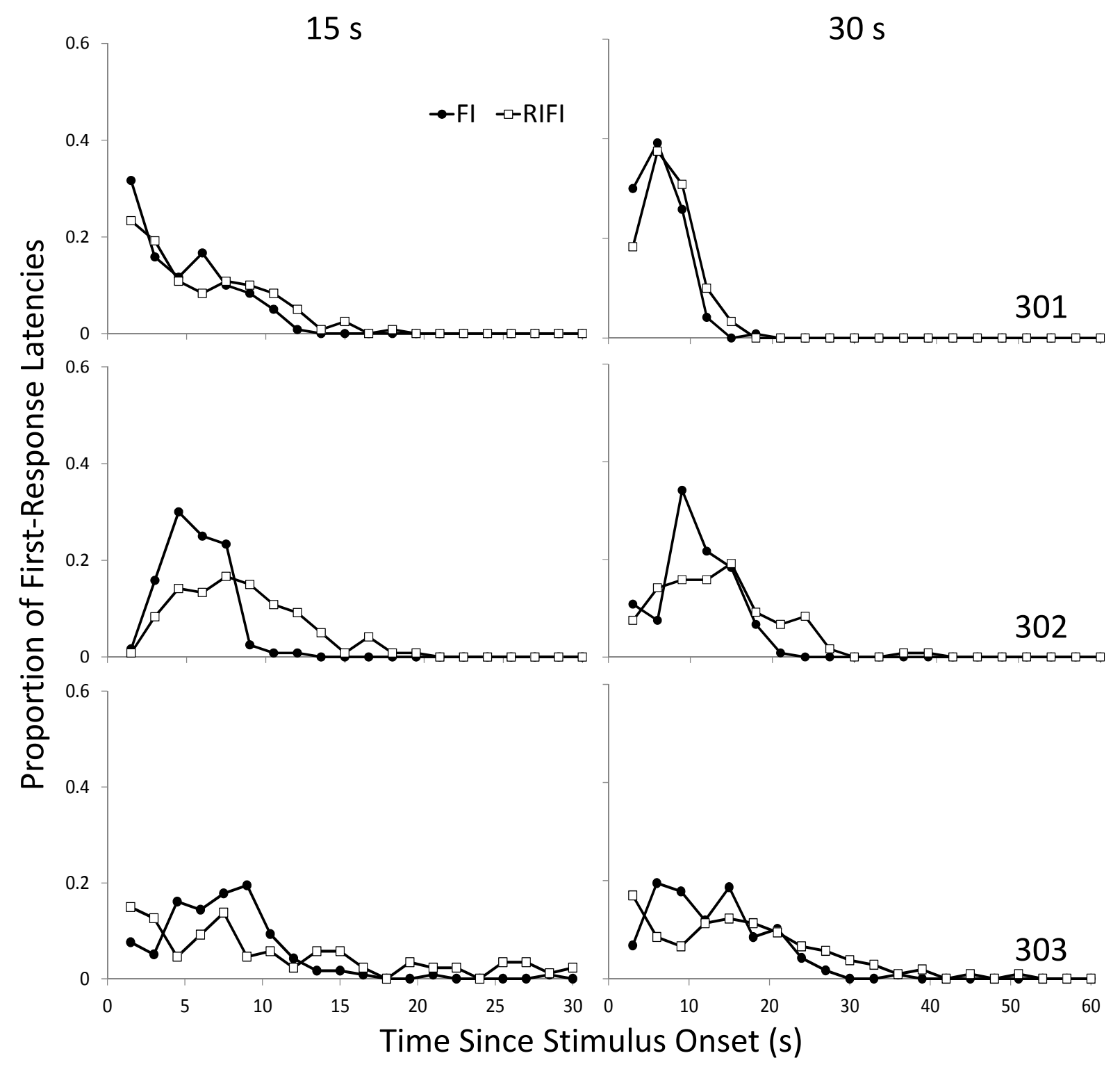

Figure 2. Frequency distributions for each pigeon in each condition of Experiment 1. Each graph shows the proportion of first-response latencies that occurred as a function of time in bins equal to $10 \%$ of the corresponding interval. 

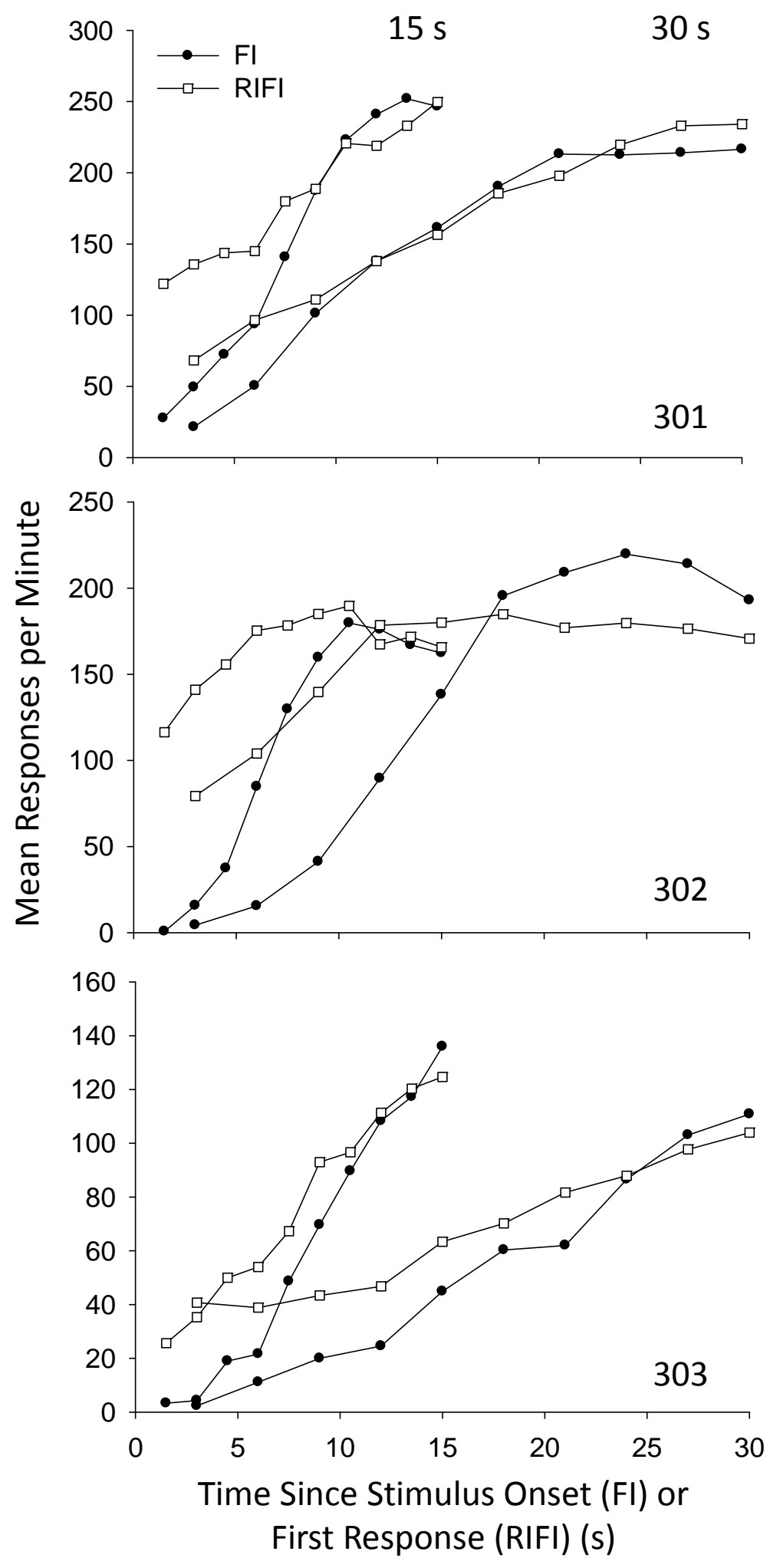

Figure 3. Mean responses per minute as a function of time in bins equal to $10 \%$ of the corresponding interval for each pigeon in each condition of Experiment 1. 


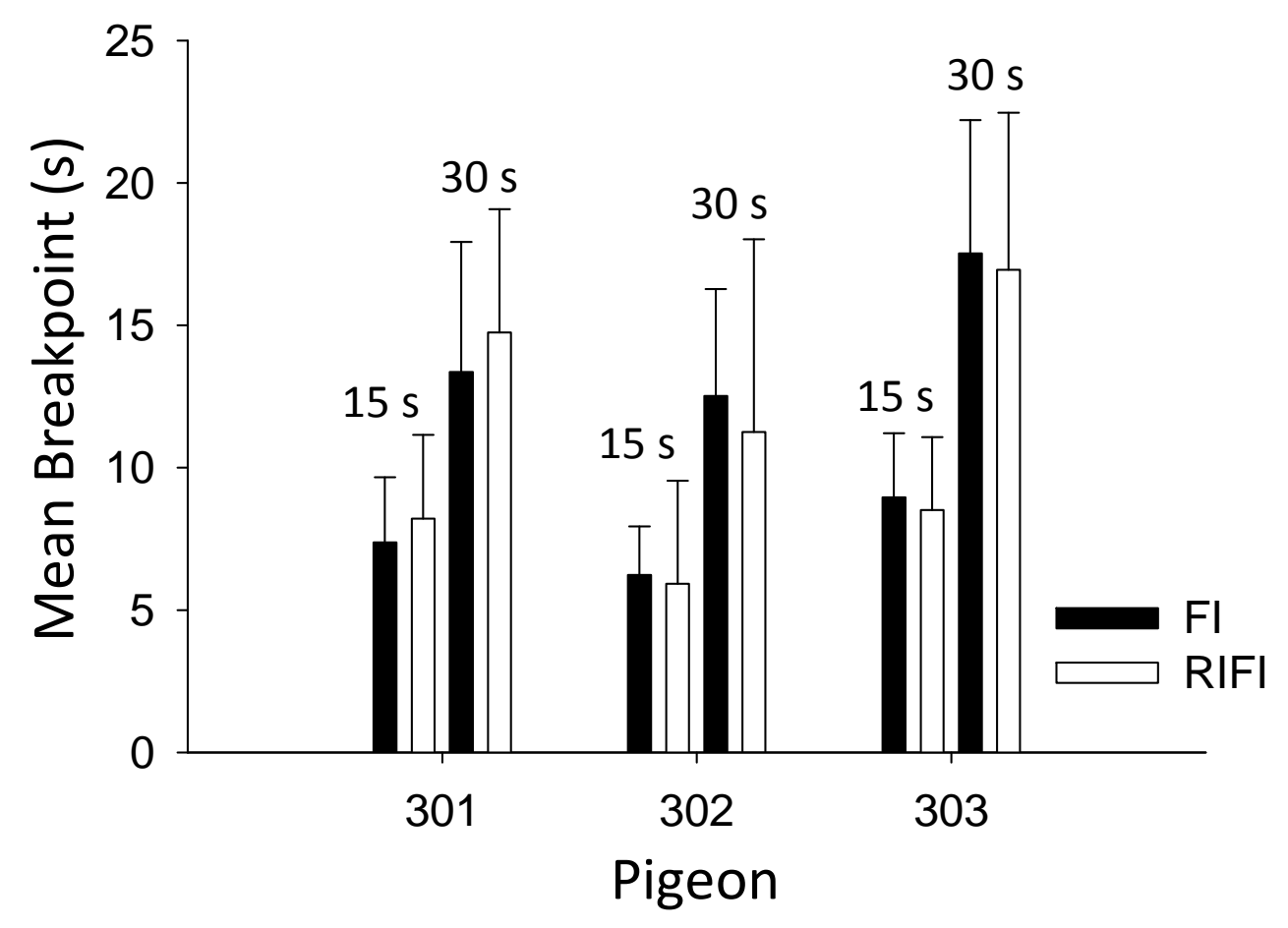

Figure 4. Mean breakpoint for each pigeon in each condition of Experiment 1. Error bars represent standard deviations. 


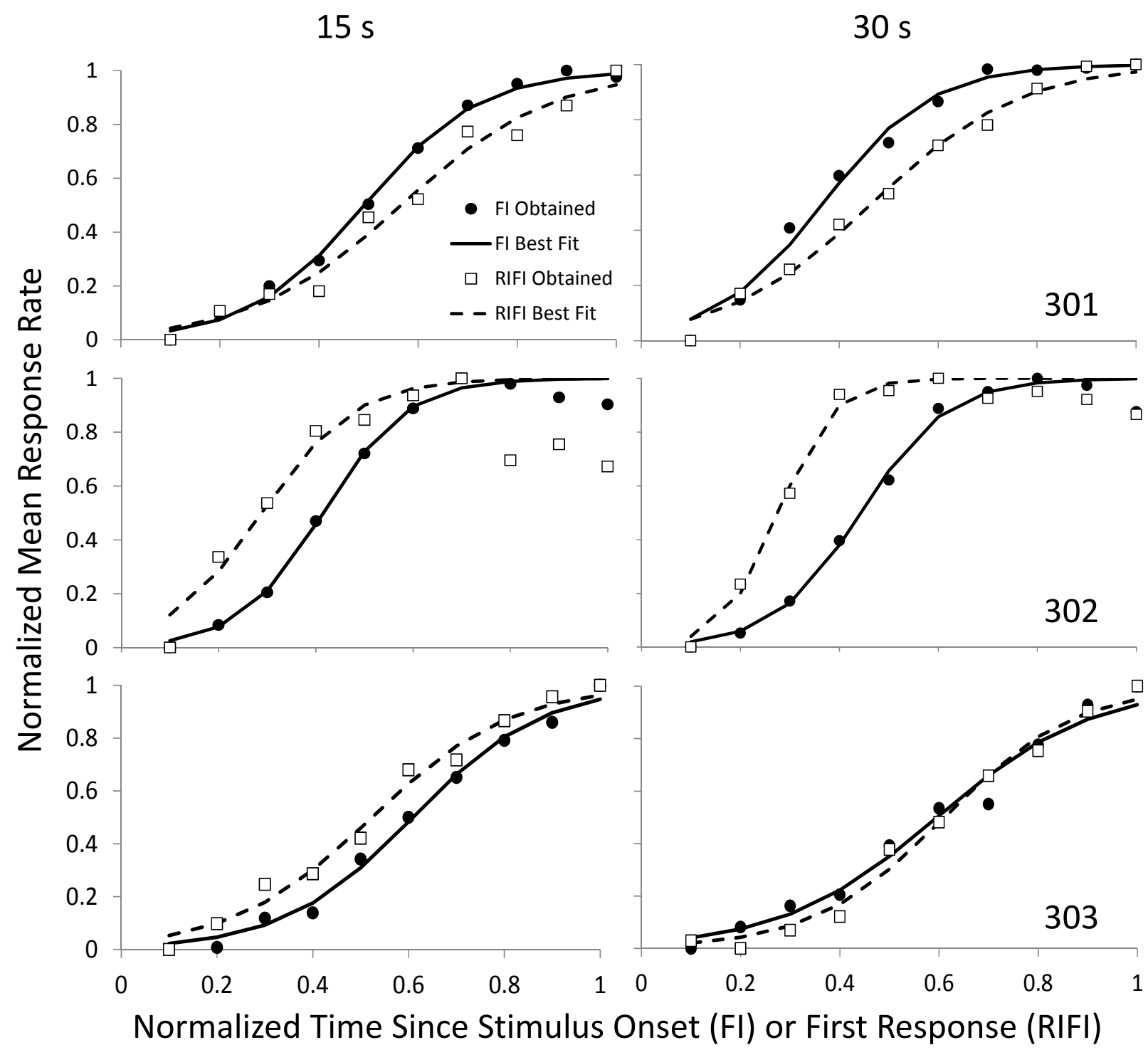

Figure 5. Normalized mean response-rate gradients as a function of normalized time for each pigeon in each condition of Experiment 1. The solid lines represent the best-fitting ogive function for the FI schedules and the dashed lines represent the best-fitting ogive function for the RIFI schedules. 


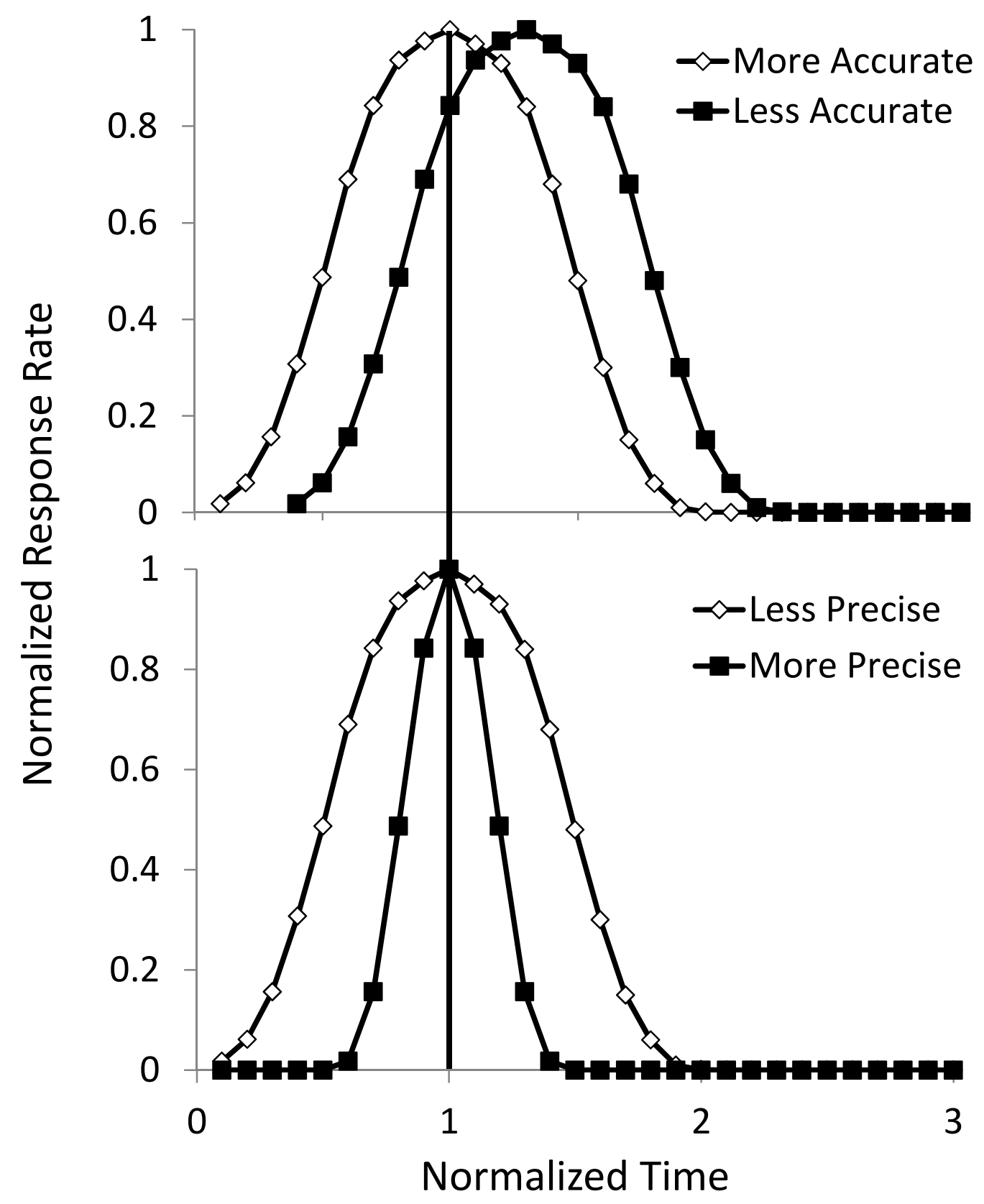

Figure 6. Hypothetical examples of differences in timing accuracy (top) and precision (bottom) in the peak procedure. Solid vertical line is the programmed time of food delivery on food trials. 


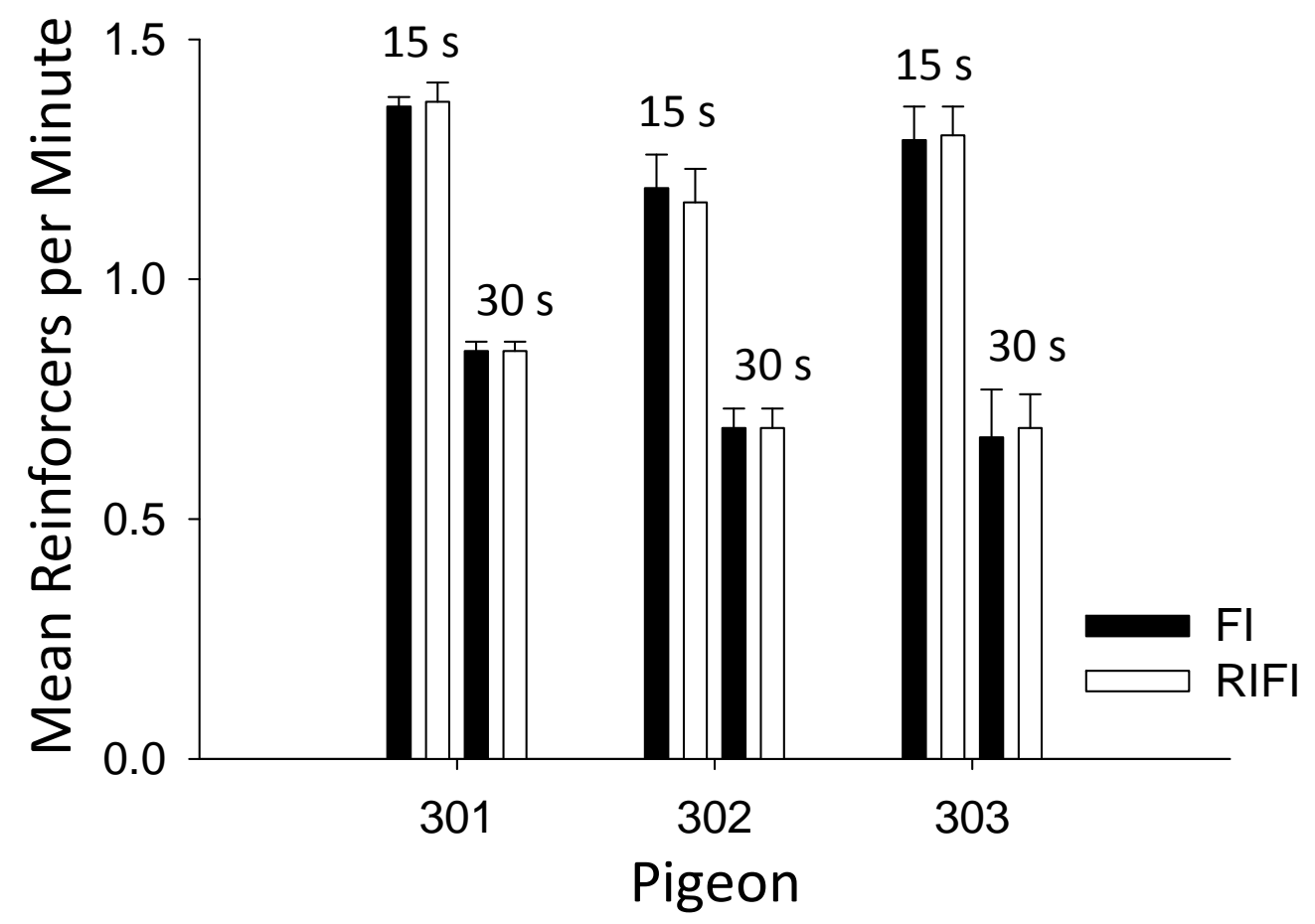

Figure 7. Mean reinforcers per minute for each pigeon in each condition of Experiment 2. Error bars represent standard deviations. 


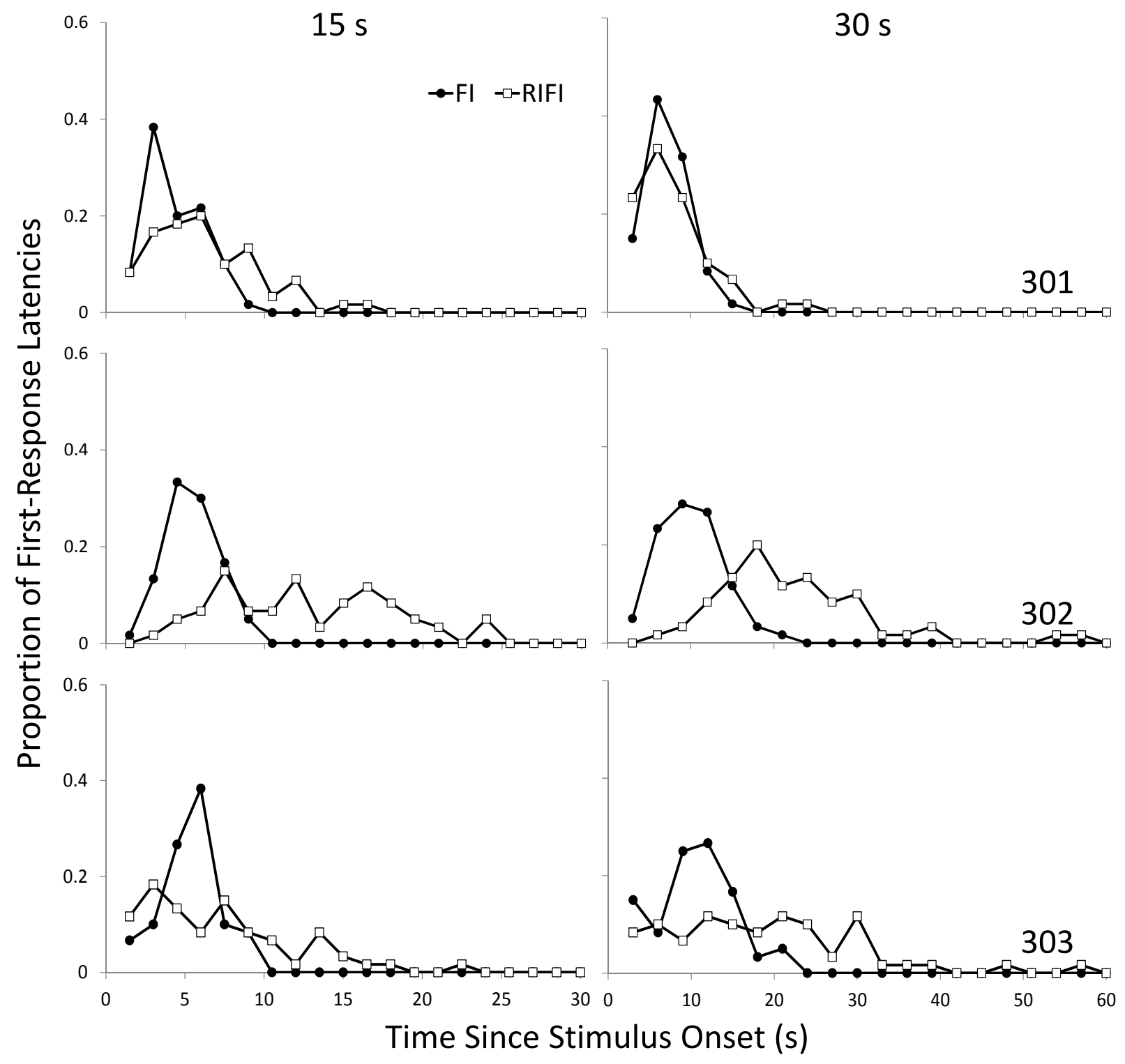

Figure 8. Frequency distributions for each pigeon in each condition of Experiment 2. Each graph shows the proportion of first-response latencies that occurred as a function of time in bins equal to $10 \%$ of the corresponding interval. 

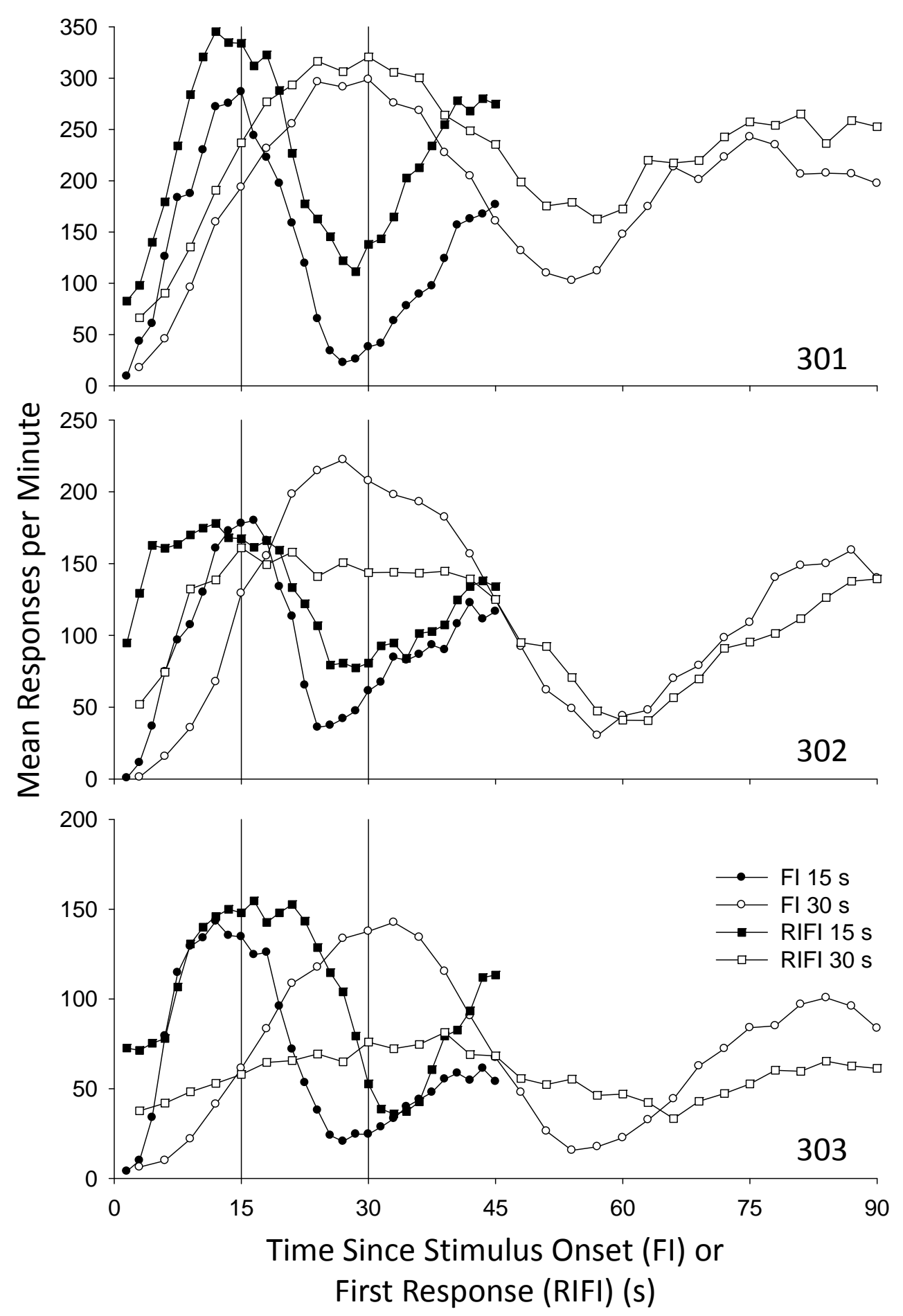

Figure 9. Mean responses per minute as a function of time in bins equal to $10 \%$ of the corresponding interval for each pigeon in each condition of Experiment 2. Solid lines represent the time of programmed food availability on food trials (at 15 and $30 \mathrm{~s}$ ). 


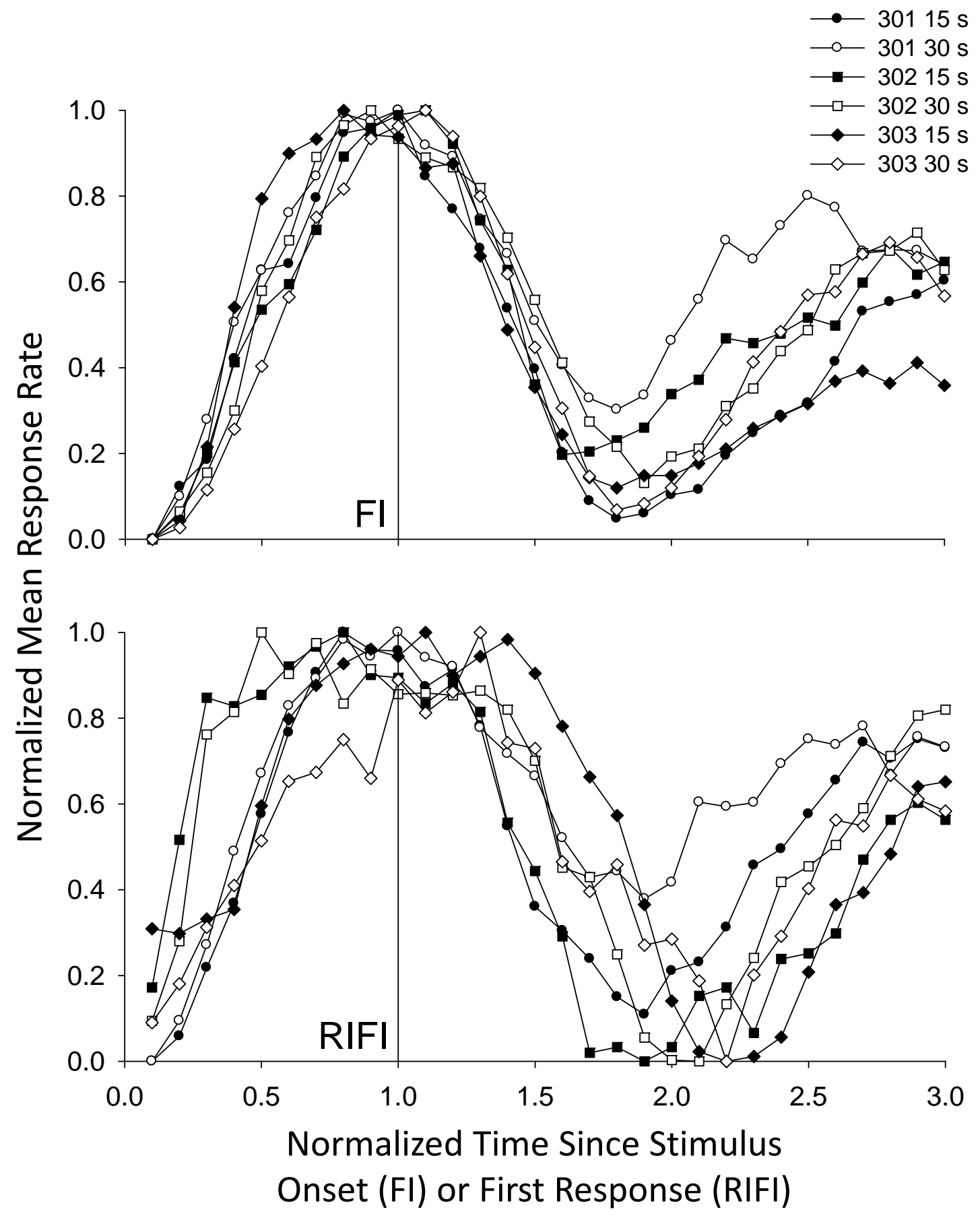

Figure 10. Normalized mean response-rate gradients as a function of normalized time for each pigeon in FI (top) and RIFI (bottom) schedules in Experiment 2. The solid lines represent the time of programmed food availability on food trials. 


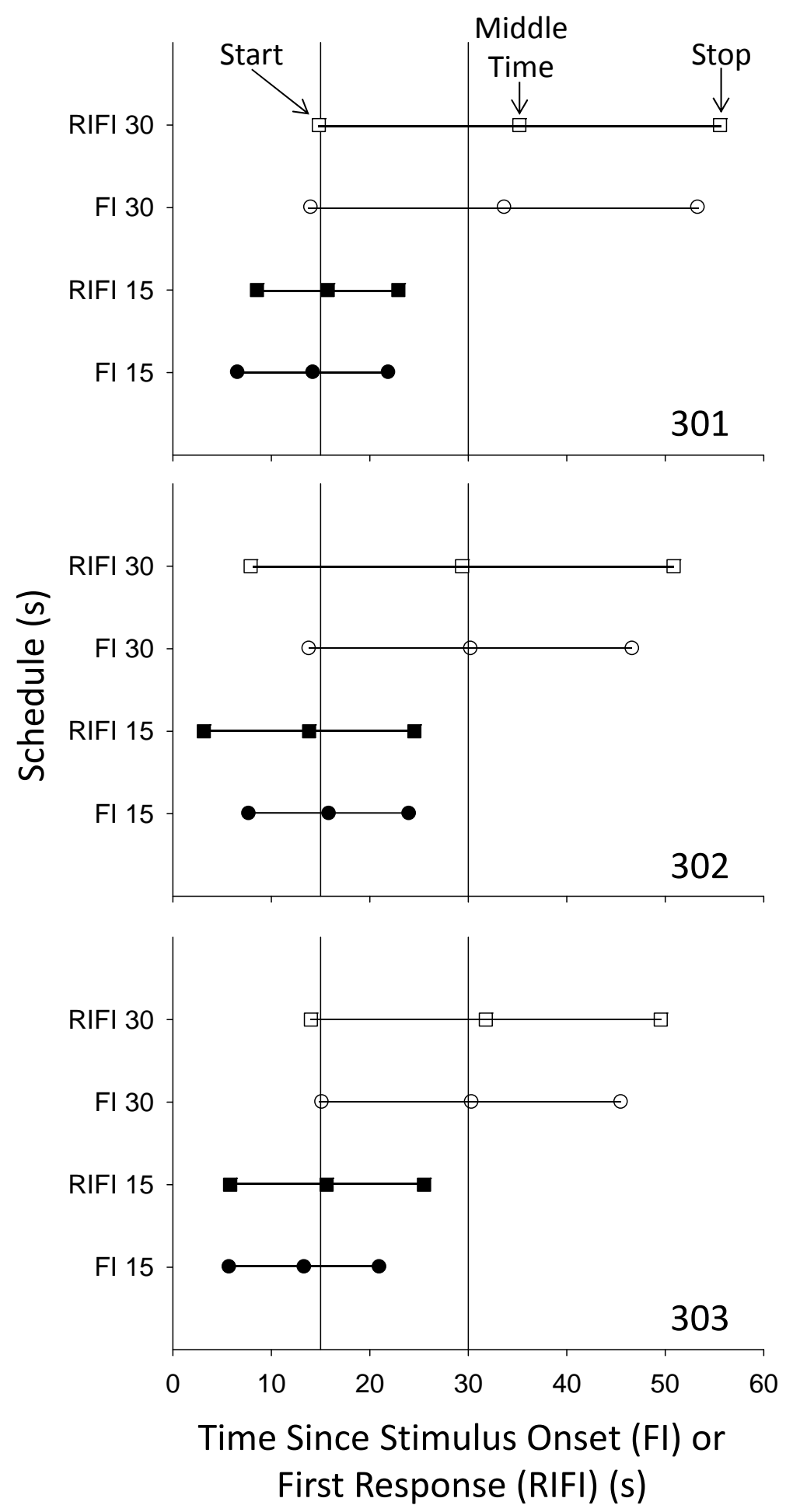

Figure 11. Mean start, middle, stop times for each pigeon in each condition of Experiment 2. The solid vertical lines represent the time of programmed food availability on food trials (15 and 30 s). 


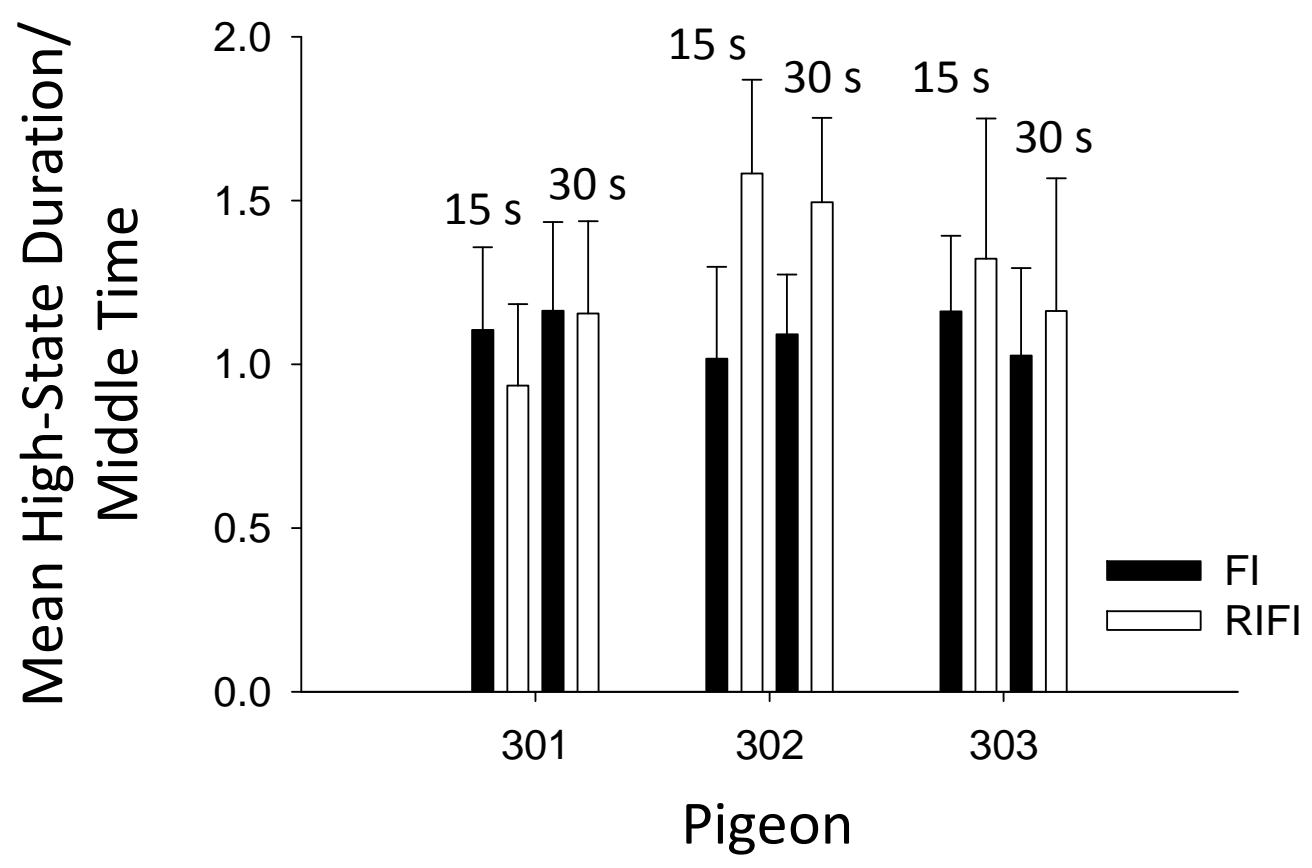

Figure 12. Mean standardized measure of precision (mean high-state duration divided by the middle time) shown for each pigeon in each condition of Experiment 2. See text for additional details. Error bars represent standard deviations. 


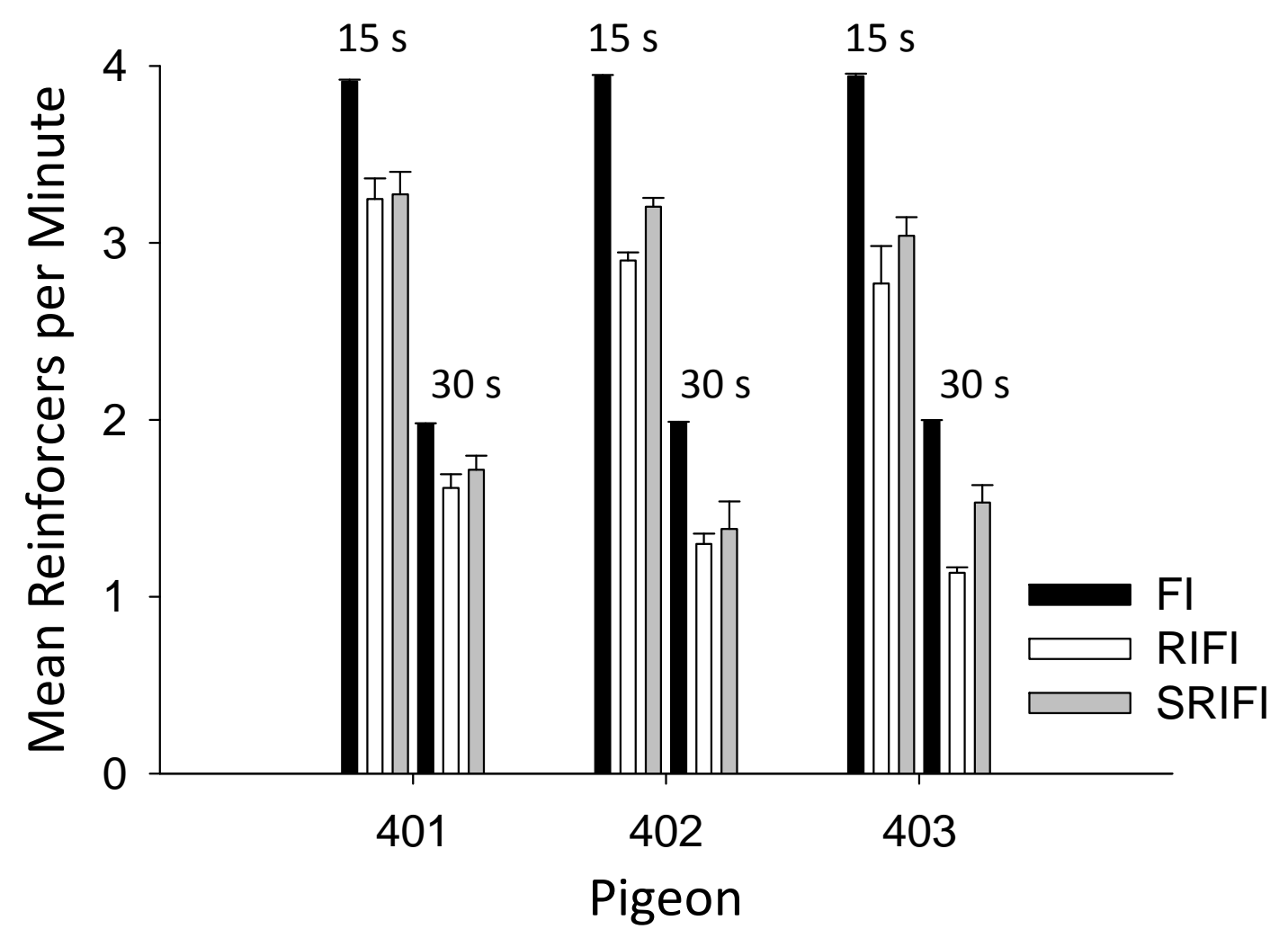

Figure 13. Mean reinforcers per minute for each pigeon in each condition of Experiment 3. Error bars represent standard deviations. SRIFI $=$ Signaled-RIFI schedule. 


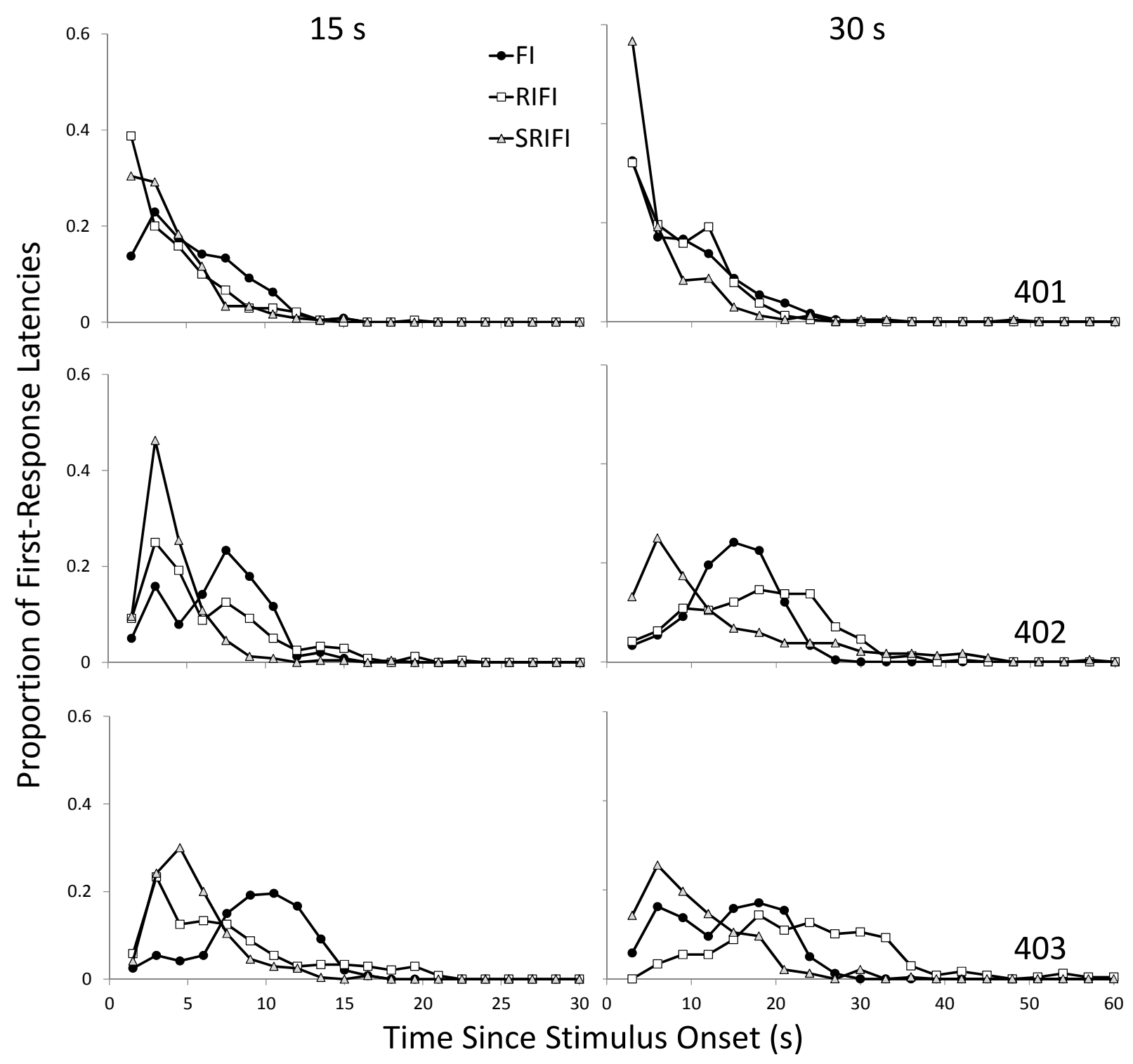

Figure 14. Frequency distributions for each pigeon in each condition of Experiment 3. Each graph shows the proportion of first-response latencies that occurred as a function of time in bins equal to $10 \%$ of the corresponding interval. SRIFI = Signaled-RIFI schedule. 

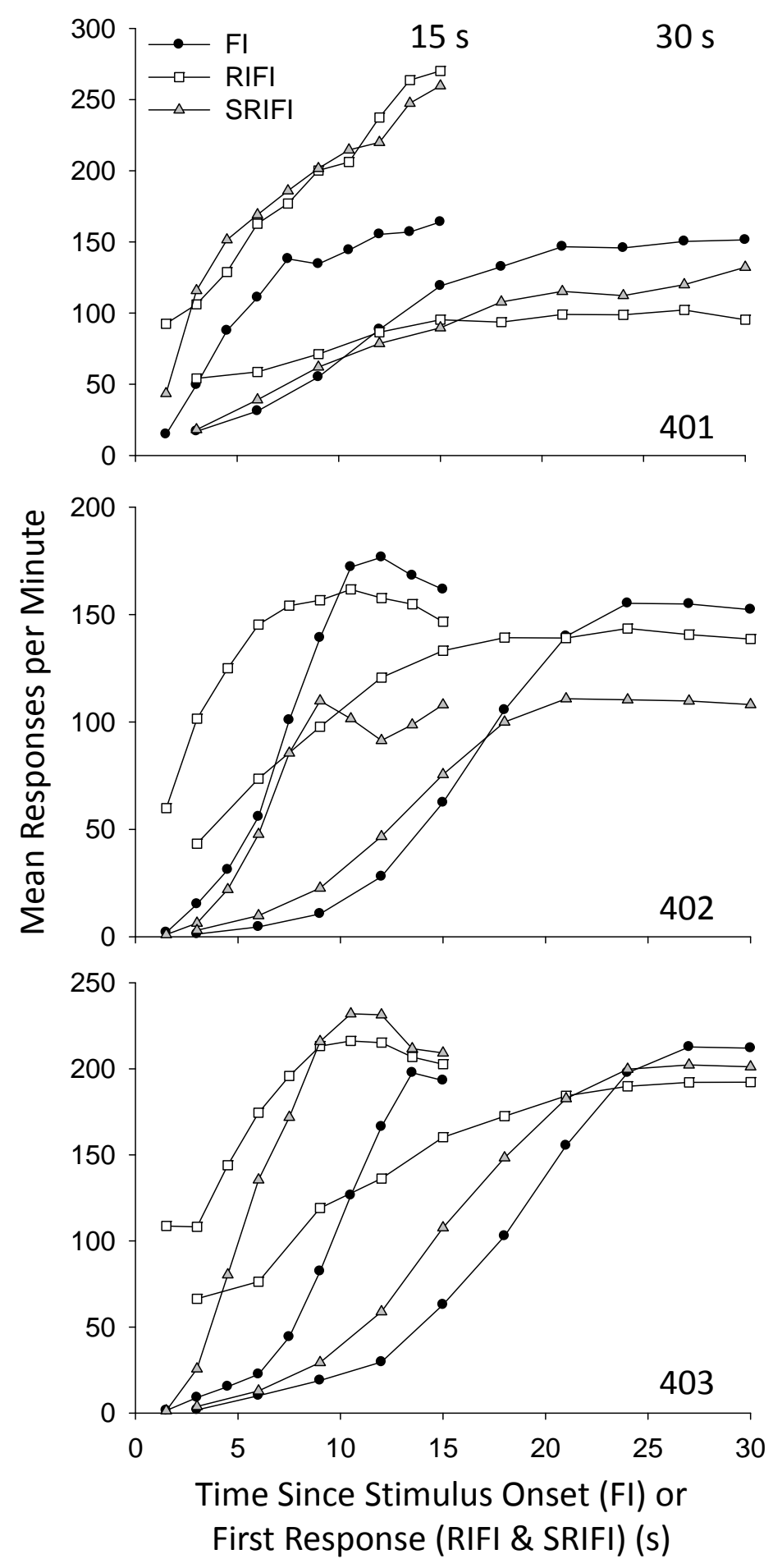

Figure 15. Mean responses per minute as a function of time in bins equal to $10 \%$ of the corresponding interval for each pigeon in each condition of Experiment 3. SRIFI = SignaledRIFI schedule. 


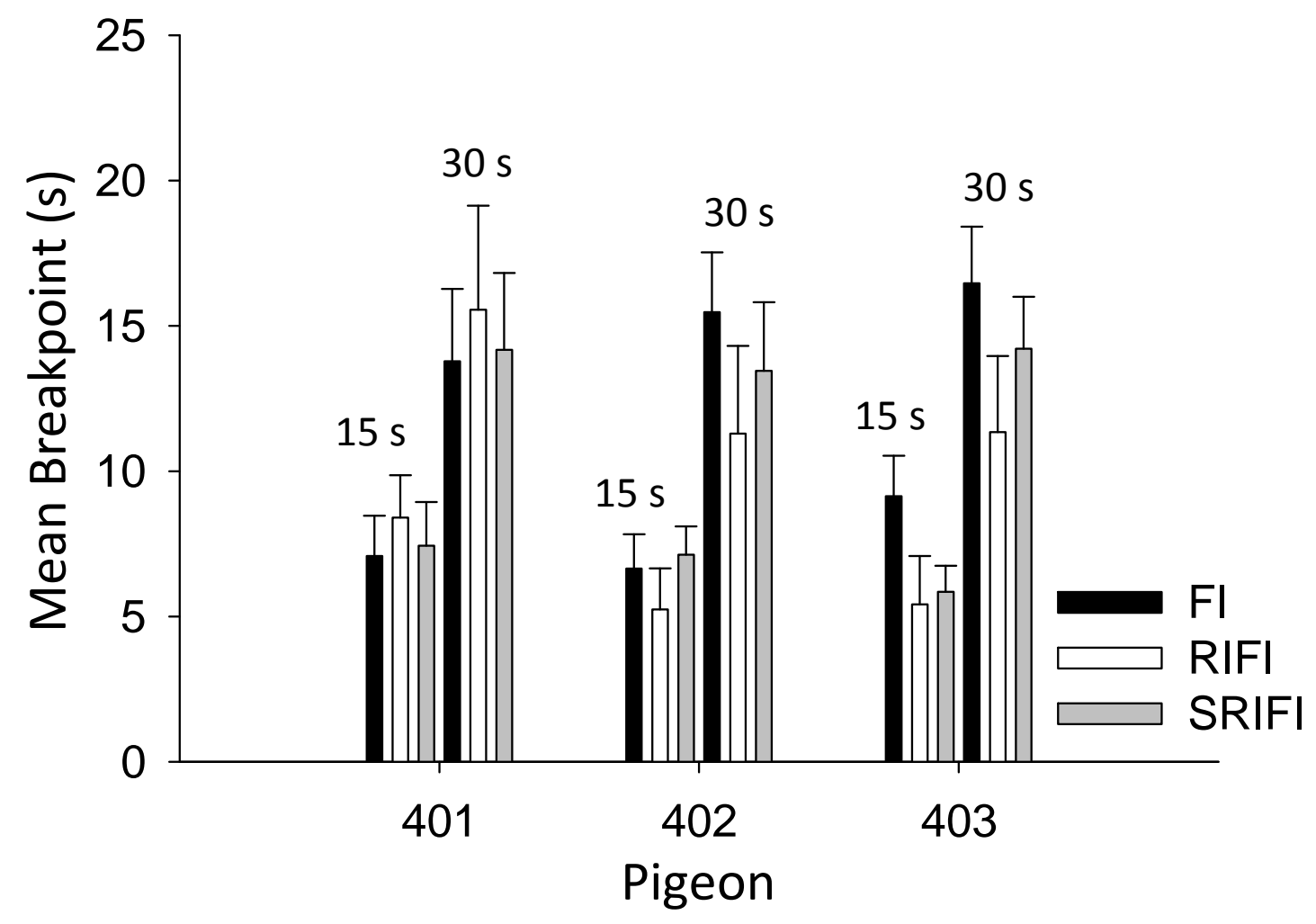

Figure 16. Mean breakpoint for each pigeon in each condition of Experiment 3. Error bars represent standard deviations. SRIFI = Signaled-RIFI schedule. 


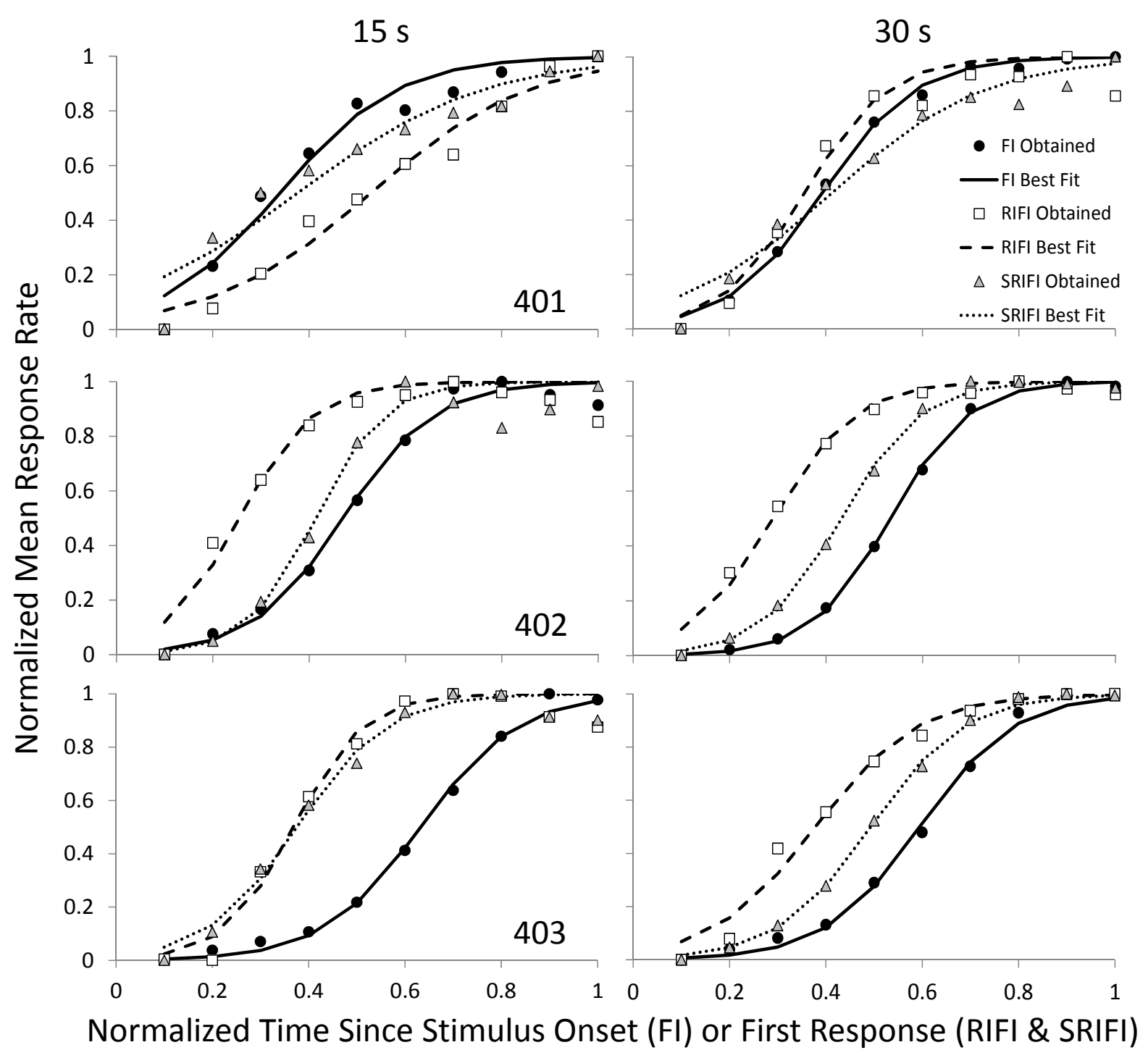

Figure 17. Normalized mean response-rate gradients as a function of normalized time for each pigeon in each condition of Experiment 3. The solid lines represent the best-fitting ogive function for the FI schedules, the dashed lines represent the best-fitting ogive function for the RIFI schedules, and the dotted lines represent the best-fitting ogive function for the SignaledRIFI schedules (SRIFI). 
Appendix A

\begin{tabular}{|c|c|c|c|c|}
\hline Page & Experiment & $\begin{array}{c}\text { Dependent } \\
\text { Measure }\end{array}$ & Test & Results/Details \\
\hline 12 & 1 & $\begin{array}{l}\text { First-response } \\
\text { latencies in FI and } \\
\text { RIFI schedules }\end{array}$ & $\begin{array}{l}\text { Repeated- } \\
\text { Measures } \\
\text { Wilcoxon Signed- } \\
\text { Rank }\end{array}$ & 6 matched pairs; $p=.028$ \\
\hline 13 & 1 & $\begin{array}{l}\text { First-response } \\
\text { latency } \\
\text { distributions }\end{array}$ & $\begin{array}{l}\text { Kolmogorov- } \\
\text { Smirnov }\end{array}$ & $\begin{array}{l}120 \text { data points in each FI versus RIFI } \\
\text { distribution; Exception: } 118 \text { (FI) versus } \\
107 \text { (RIFI) in 30-s schedules for Pigeon } \\
303\end{array}$ \\
\hline 14 & 1 & $\begin{array}{l}\text { Trials excluded } \\
\text { for breakpoint } \\
\text { analysis }\end{array}$ & RM ANOVA & $\begin{array}{l}\text { Schedule: } F(1,2)=1.41, p=.357 \\
\text { Interval: } F(1,2)=0.04, p=.853 ; \\
\text { Interaction: } F(1,2)=12.00, p=.074\end{array}$ \\
\hline 14 & 1 & Breakpoints & RM ANOVA & $\begin{array}{l}\text { Schedule: } F(1,2)=0.01, p=.926 \\
\text { Interval: } F(1,2)=67.83, p=.014 \\
\text { Interaction: } F(1,2)=0.16, p=.725\end{array}$ \\
\hline 16 & 1 & $\begin{array}{l}\text { Parameter } a \\
\text { estimates }\end{array}$ & RM ANOVA & $\begin{array}{l}\text { Schedule: } F(1,2)=0.20, p=.696 ; \\
\text { Interval: } F(1,2)=0.19, p=.705 ; \\
\text { Interaction: } F(1,2)=.043, p=.578\end{array}$ \\
\hline 16 & 1 & $\begin{array}{l}\text { Parameter } b \\
\text { estimates }\end{array}$ & RM ANOVA & $\begin{array}{l}\text { Schedule: } F(1,2)=0.11, p=.771 ; \\
\text { Interval: } F(1,2)=1.923, p=.300 ; \\
\text { Interaction: } F(1,2)=1.96, p=.296\end{array}$ \\
\hline 23 & 2 & $\begin{array}{l}\text { First-response } \\
\text { latencies in FI and } \\
\text { RIFI schedules }\end{array}$ & $\begin{array}{l}\text { Repeated- } \\
\text { Measures } \\
\text { Wilcoxon Signed- } \\
\text { Rank }\end{array}$ & 6 matched pairs; $p=.046$ \\
\hline 23 & 2 & $\begin{array}{l}\text { First-response } \\
\text { latency } \\
\text { distributions }\end{array}$ & $\begin{array}{l}\text { Kolmogorov- } \\
\text { Smirnov }\end{array}$ & $\begin{array}{l}60 \text { data points in each FI versus RIFI } \\
\text { distribution }\end{array}$ \\
\hline 26 & 2 & $\begin{array}{l}\text { Trials excluded in } \\
\text { FI and RIFI } \\
\text { schedules for low- } \\
\text { high-low analysis }\end{array}$ & RM ANOVA & $\begin{array}{l}\text { Schedule: } F(1,2)=2.53, p=.253 \text {; } \\
\text { Interval: } F(1,2)=0.98, p=.427 \\
\text { Interaction: } F(1,2)=0.00, p=1.0\end{array}$ \\
\hline 26 & 2 & Middle times & RM ANOVA & $\begin{array}{l}\text { Schedule: } F(1,2)=0.24, p=.621 ; \\
\text { Interval: } F(1,2)=167.99, p=.006 ; \\
\text { Interaction: } F(1,2)=0.04, p=.856\end{array}$ \\
\hline 26 & 2 & $\begin{array}{l}\text { High-state } \\
\text { durations }\end{array}$ & $\begin{array}{l}\text { Repeated- } \\
\text { Measures } \\
\text { Wilcoxon Signed- } \\
\text { Rank }\end{array}$ & 6 matched pairs; $p=.046$ \\
\hline
\end{tabular}


$27 \quad 2$

$33 \quad 3$

$33 \quad 3$

$34 \quad 3$

$34 \quad 3$

$34 \quad 3$

$36 \quad 3$

$37 \quad 3$

$38 \quad 3$

$38 \quad 3$
Standardized index of timing precision

Kolmogorov-

Smirnov

Reinforcement rates

Reinforcement rates

First-response latencies: FI versus RIFI

First-response latencies: FI versus SRIFI

First-response latencies: RIFI versus SRIFI

Trials excluded for breakpoint analysis

Breakpoints

Parameter $a$ estimates

Parameter $b$ estimates
Repeated-

Measures

Wilcoxon Signed-

Rank

Repeated-

Measures

Wilcoxon Signed-

Rank

Repeated-

Measures

Wilcoxon Signed-

Rank

RM ANOVA

RM ANOVA

RM ANOVA

RM ANOVA
Pooled across all pigeons: 290 data points in FI distribution; 275 data points in RIFI distribution

Schedule: $F(2,4)=30.75, p=.004$;

Interval: $F(1,2)=2819.03, p<.001$;

Interaction: $F(2,4)=9.68, p=.029$

FI15 vs RIFI15: $t(2)=6.29, p=.024$;

FI30 vs RIFI30: $t(2)=4.385, p=.048$;

FI15 vs SRIFI15: $t(2)=11.30, p=.008$;

FI30 vs SRIFI30: $t(2)=4.47, p=.047$;

RIFI15 vs SRIFI15: $t(2)=1.92, p=.195$;

RIFI30 vs SRIFI30: $t(2)=1.92, p=.195$

6 matched pairs; $p=.917$

6 matched pairs; $p=.028$

6 matched pairs; $p=.173$

Schedule: $F(2,4)=5.06, p=.08$;

Interval: $F(1,2)=0.05, p=.845$;

Interaction: $F(2,4)=1.083, p=.421$

Schedule: $F(2,4)=1.07, p=.425$;

Interval: $F(1,2)=5203.44, p<.001$;

Interaction: $F(2,4)=0.86, p=.488$

Schedule: $F(2,4)=2.19, p=.172$;

Interval: $F(1,2)=0.37, p=.605$;

Interaction: $F(2,4)=1.16, p=.4$

Schedule: $F(2,4)=0.15, p=.867$;

Interval: $F(1,2)=1.75, p=.317$;

Interaction: $F(2,4)=0.35, p=.725$ 


\section{Appendix B}

Raster Plots

Individual raster plots showing responding from Experiments 1-3. Responses are indicated by black dots and are separated by trial on the y-axis. These raster plots display how responding was distributed across trials on a trial-by-trial basis. See individual figure captions for details. 


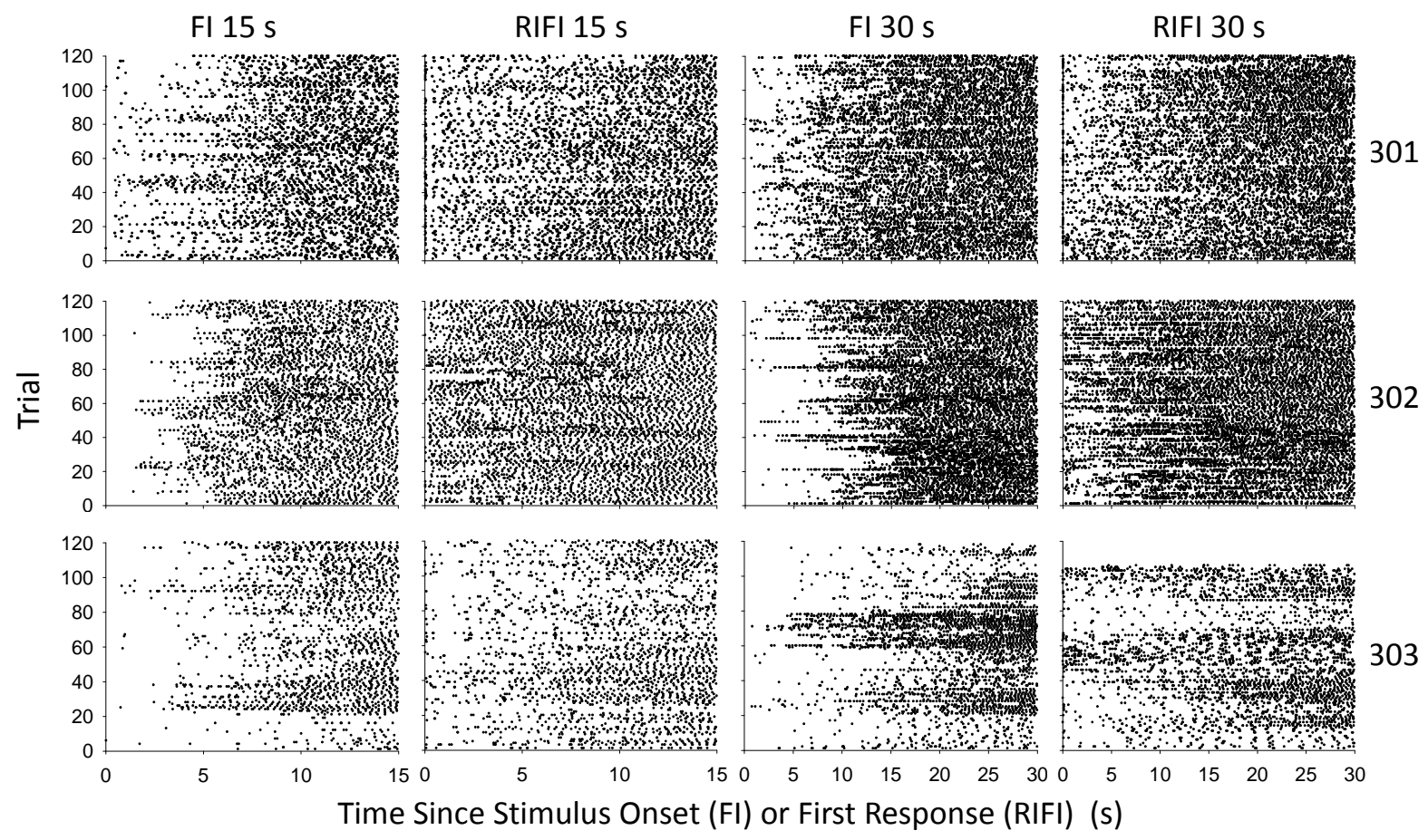

Figure B1. Individual raster plots showing responding from each component of the last six sessions of each condition of Experiment 1 as a function of time since stimulus onset (FI) or first response (RIFI). In both FI and RIFI schedules, the plots darken as time to food decreased and more responses were recorded. In the FI schedules, however, there were fewer responses early in the interval compared to corresponding RIFI schedules. 


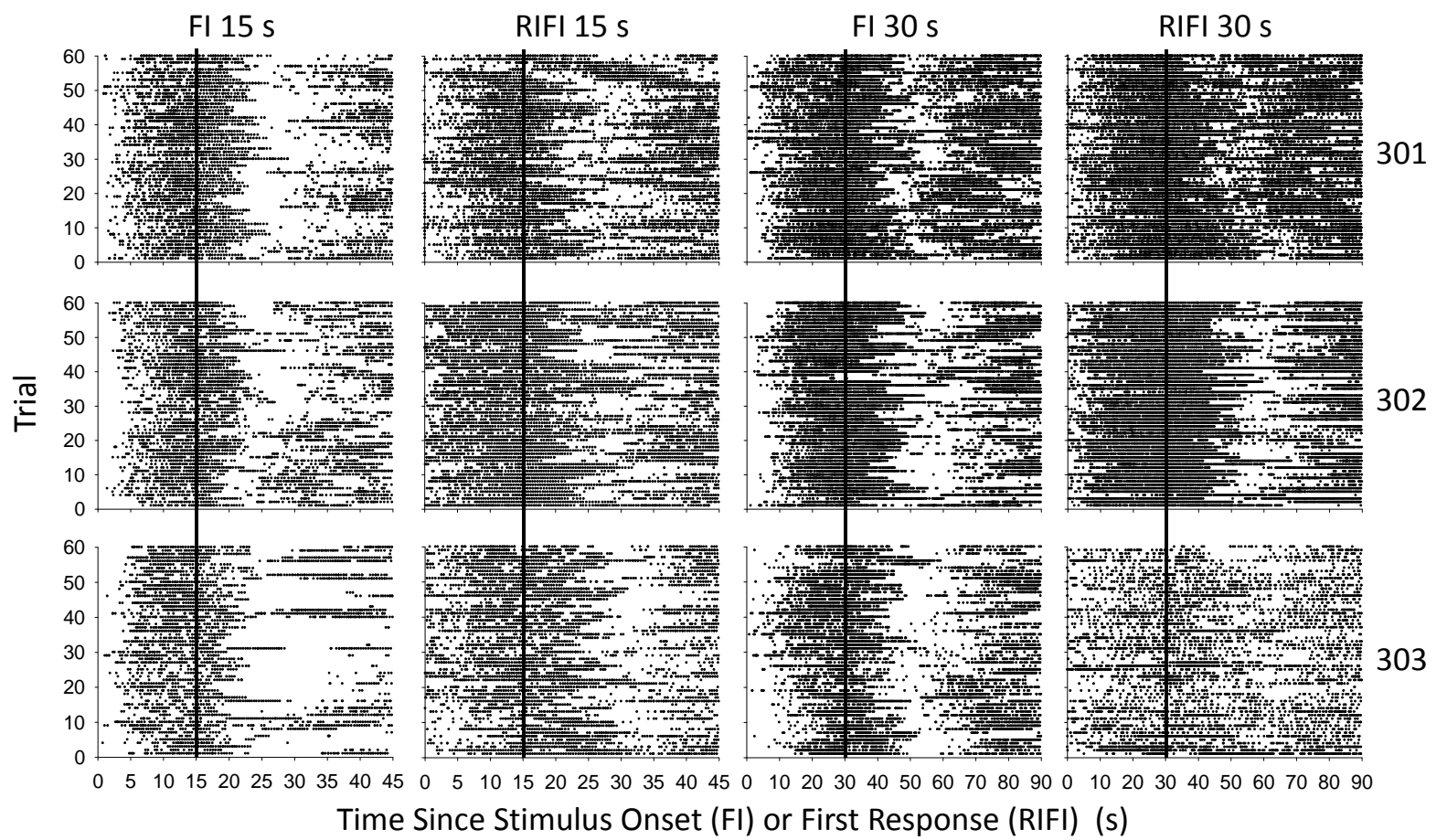

Figure B2. Individual raster plots showing responding from each component in the last six sessions of each condition of Experiment 2 as a function of time since stimulus onset (FI) or first response (RIFI). The solid vertical lines on each graph indicate the time in which food was available on food trials (i.e., 15 and 30 s). In both FI and RIFI schedules, the plots darken as more responses were recorded before and after the approximate time of food delivery on food trials. The plots also darken as response rates increased at the end of the no-food trial. There are some important differences between the FI and RIFI plots though. First, consistent with Experiment 1, more responses were occurring at the start of RIFI trials than FI trials. Second, for Pigeons 302 and 303 in particular, the overall area of the dark bands of responses surrounding the typical time of food delivery were larger in the RIFI than FI schedules. Finally, the distinction between when response rates decreased after the time of typical food delivery and when they began to increase toward the end of the no-food trial was less distinguishable in the RIFI schedules compared to corresponding FI schedules. 


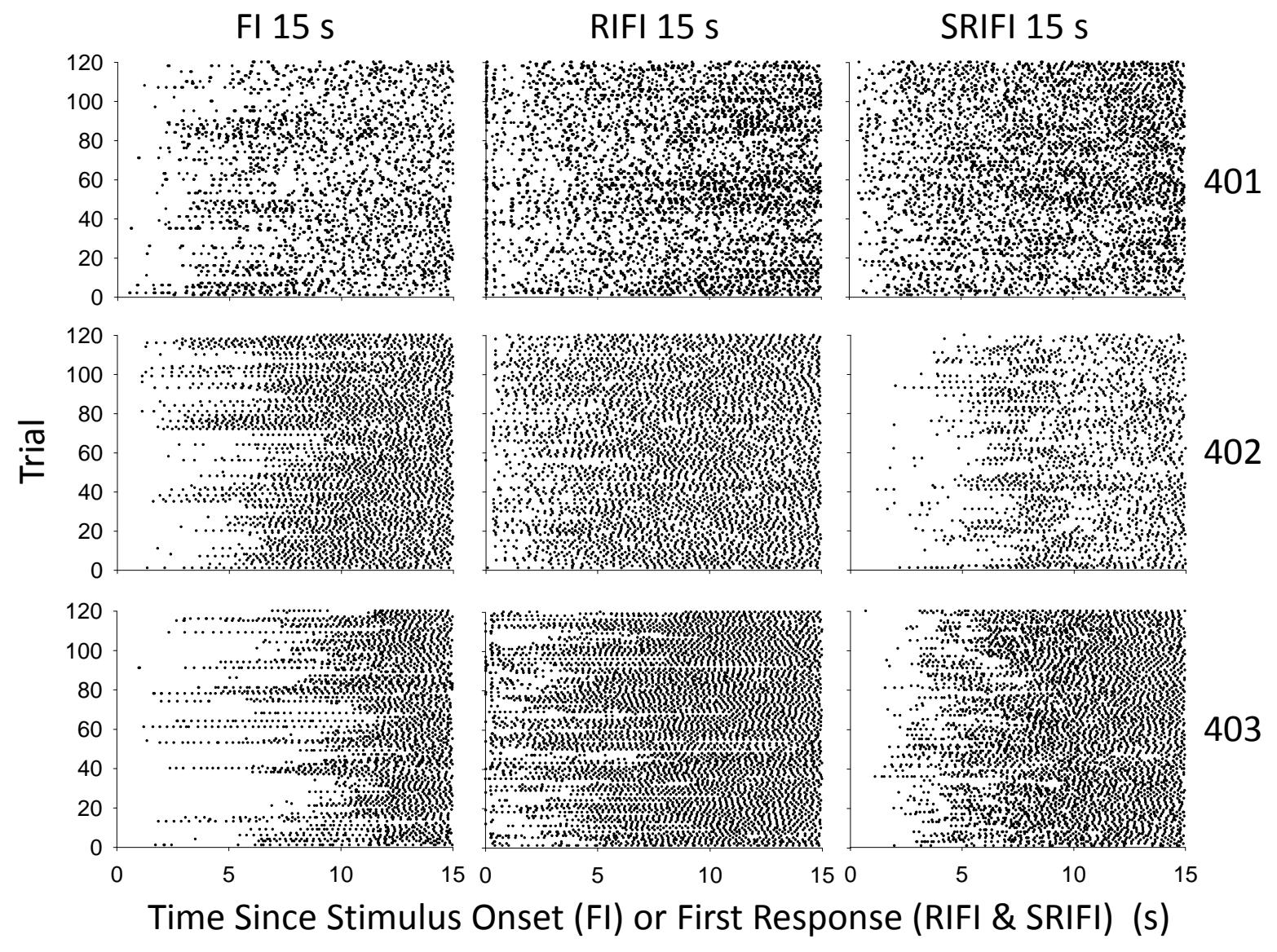

Figure B3. Individual raster plots showing responding in the last six sessions of each 15-s interval condition of Experiment 3 as a function of time since stimulus onset (FI) or first response (RIFI and Signaled-RIFI). In FI, RIFI, and Signaled-RIFI (SRIFI) schedules, the plots darken as time to food decreased and more responses were recorded. In the FI and Signaled-RIFI schedules, however, there were fewer responses early in the interval compared to corresponding RIFI schedules. This was especially true for Pigeons 402 and 403. 


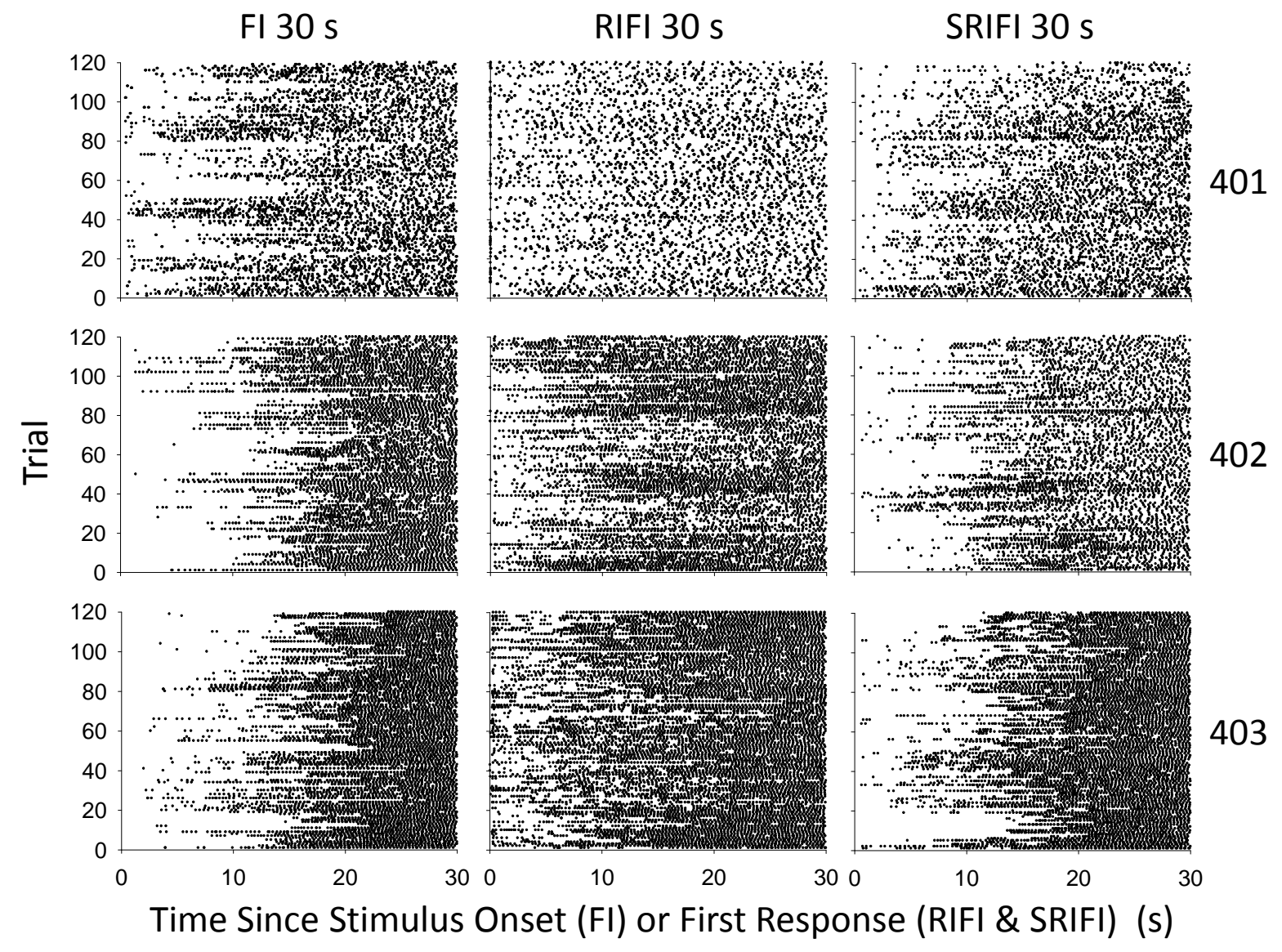

Figure B4. Individual raster plots showing responding in the last six sessions of each 30-s interval condition of Experiment 3 as a function of time since stimulus onset (FI) or first response (RIFI and Signaled-RIFI). In FI, RIFI, and Signaled-RIFI (SRIFI) schedules, the plots darken as time to food decreased and more responses were recorded. In the FI and Signaled-RIFI schedules, however, there were fewer responses early in the interval compared to corresponding RIFI schedules. This was especially true for Pigeons 402 and 403. 